NASA Technical Memorandum 106958

\title{
The Effect of Adding Roughness and Thickness to a Transonic Axial Compressor Rotor
}

Kenneth L. Suder, Rodrick V. Chima, and Anthony J. Strazisar Lewis Research Center

Cleveland, Ohio

William B. Roberts

Flow Application Research and Sermatech International Inc.

Fremont, California

Prepared for the

39th International Gas Turbine and Aeroengine Congress and Exposition sponsored by the American Society of Mechanical Engineers The Hague, Netherlands, June 13-16, 1994

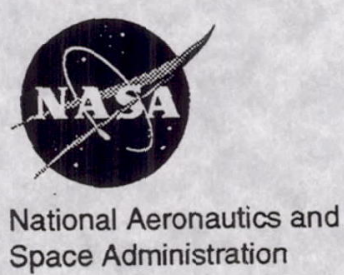

Space Administration 


\title{
THE EFFECT OF ADDING ROUGHNESS AND THICKNESS TO A TRANSONIC AXIAL COMPRESSOR ROTOR
}

\author{
Kenneth L. Suder, Rodrick V. Chima, Anthony J. Strazisar \\ NASA-Lewis Research Center \\ Cleveland, Ohio \\ William B. Roberts \\ Flow Application Research and Sermatech International Inc. \\ Fremont, California
}

\begin{abstract}
The performance deterioration of a high speed axial compressor rotor due to surface roughness and airfoil thickness variations is reported. A $0.025 \mathrm{~mm}(0.001$ in.) thick rough coating with a surface finish of 2.54-3.18 RMS $\mu \mathrm{m}$ (100-125 RMS microinches) is applied to the pressure and suction surface of the rotor blades. Coating both surfaces increases the leading edge thickness by $10 \%$ at the hub and $20 \%$ at the tip. Application of this coating results in a loss in efficiency of 6 points and a $9 \%$ reduction in the pressure ratio across the rotor at an operating condition near the design point. To separate the effects of thickness and roughness, a smooth coating of equal thickness is also applied to the blade. The smooth coating surface finish is $0.254-0.508 \mathrm{RMS} \mu \mathrm{m}$ (10-20 RMS microinches), compared to the bare metal blade surface finish of 0.508 RMS $\mu$ m (20 RMS microinches). The smooth coating results in approximately half of the performance deterioration found from the rough coating. Both coatings are then applied to different portions of the blade surface to determine which portions of the airfoil are most sensitive to thickness/roughness variations.
\end{abstract}

Aerodynamic performance measurements are presented for a number of coating configurations at $60 \%, 80 \%$, and $100 \%$ of design speed. The results indicate that thickness/roughness over the first $10 \%$ of blade chord accounts for virtually all of the observed performance degradation for the smooth coating, compared to about $70 \%$ of the observed performance degradation for the rough coating.

The performance deterioration is investigated in more detail at design speed using laser anemometer measurements as well as predictions generated by a quasi-3D Navier-Stokes flow solver which includes a surface roughness model. Measurements and analysis are performed on the baseline blade and the full-coverage smooth and rough coatings. The results indicate that coating the blade causes a thickening of the blade boundary layers. The interaction between the rotor passage shock and the thickened suction surface boundary layer then results in an increase in blockage which reduces the diffusion level in the rear half of the blade passage, thus reducing the aerodynamic performance of the rotor.

\section{NOMENCLATURE}

$\begin{array}{ll}\mathrm{H} & \text { Total enthalpy } \\ \dot{m} & \text { Massflow rate, } \mathrm{kg} / \mathrm{s} \\ \mathrm{M}_{\mathrm{rel}} & \text { Relative Mach number } \\ \mathrm{P}_{4} & \text { Total pressure at Station 4, see Figure } 2 \\ \mathrm{PR} & \text { - Total pressure ratio } \\ \mathrm{P}_{\text {ref }} & \text { Standard-day total pressure, } 101325 \mathrm{n} / \mathrm{m}^{2} \\ \mathrm{ps} & \text { Denotes pressure surface } \\ \mathrm{r} & \text { Radius, m } \\ \mathrm{ss} & \text { Denotes suction surface } \\ \mathrm{T}_{4} & \text { Total temperature at Station 4, see Figure 2 } \\ \mathrm{T}_{\text {ref }} & \text { Standard day total temperature, 288.2 K }\end{array}$

\section{INTRODUCTION}

Industries that use gas turbine engines have a continuing need for data on in-service performance loss due to component deterioration. This need is especially great in the airline industry, for which fuel burn and performance retention in high by-pass ratio turbofan engines is a major concern. The single component of a high bypass engine that absorbs the greatest amount of energy and accounts for the greatest fuel burn is the transonic fan. Furthermore, fan blades suffer the most rapid erosion and surface roughening due to lower-atmosphere particulates and runway debris. If the performance effects of fan blade in-service deterioration can be quantified, cost-effective repair strategies and replacement intervals can be deduced. In addition, understanding of the mechanisms by which blade deterioration degrades performance may 
allow manufacturers to develop design and manufacturing strategies aimed at minimizing long-term performance deterioration.

Engine component deterioration and overall loss in performance have been documented by a number of investigators, including Sallee et al. (1978), Kramer et al. (1980), Covey et al. (1980), and the DOE/FAA Symposium (1981). Since turbomachinery blading performance loss is generally attributed to increased surface roughness as well as particulate impact damage to blade leading edges, a number of investigators have studied the effect of surface roughness on blading performance. The effects of roughness on turbine aerodynamic performance have been investigated experimentally by Roelke and Haas (1982) and Boynton et al. (1992). Boyle (1993) recently predicted the efficiency loss due to roughness measured by Boynton by using a quasi-3D Navier-Stokes analysis in which he augmented a mixing length model to account for the effects of surface roughness. The effect of roughness on compressor blade aerodynamic performance was reported by Moses and Serovy (1951), who documented the performance changes which resulted from polishing an initially rough blade. Reid and Urasek (1973) investigated the effect of leading edge thickness by documenting the change in performance of a transonic axial-flow fan as a result of cutting back the rotor leading edge. While documenting that roughness and leading edge thickness have an impact on the aerodynamic performance of turbomachinery blading, these previous investigations have not provided a definitive explanation of the mechanism through which roughness impacts performance.

The present investigation was triggered by the application of a special anti-reflective paint to a transonic compressor rotor. The paint derived its anti-reflective properties from the presence of small silica particles embedded in the paint, which create a rough surface that diffuses rather than reflects incident light. The paint was applied during the laser anemometer investigation of the rotor flow field reported by Suder and Celestina (1994) in an attempt to suppress laser light reflections from the blading. However, the painted rotor suffered a significant deterioration in performance, with pressure ratio dropping by $9 \%$ and efficiency dropping by 6 points at an operating condition near the design point. When the paint was removed, the aerodynamic performance returned to its previous level. As a result, the anemometer optics and electronics were modified to reject light reflected from the blading, and the paint was not used by Suder and Celestina while acquiring laser anemometer measurements.

Comparison of surface finish measurements from the painted test rotor and a typical aircraft gas turbine engine fan blade prior to blade refurbishment showed that the anti-reflective paint provided roughness levels which were a reasonable model of in-service roughness levels. Therefore, at the conclusion of the previous test program, the paint was once again applied to the rotor to study the effects of roughness on performance deterioration.

Figure 1 shows a 7.5X photograph of the fan blade leading edge and the test rotor leading edge with the rough paint applied. There are two important differences between the in-service damage observed on the engine fan blade and the roughness applied to the research rotor in this experiment. First, the fan blade leading edge is visibly pitted due to particle impact, as can be seen in Figure 1b,

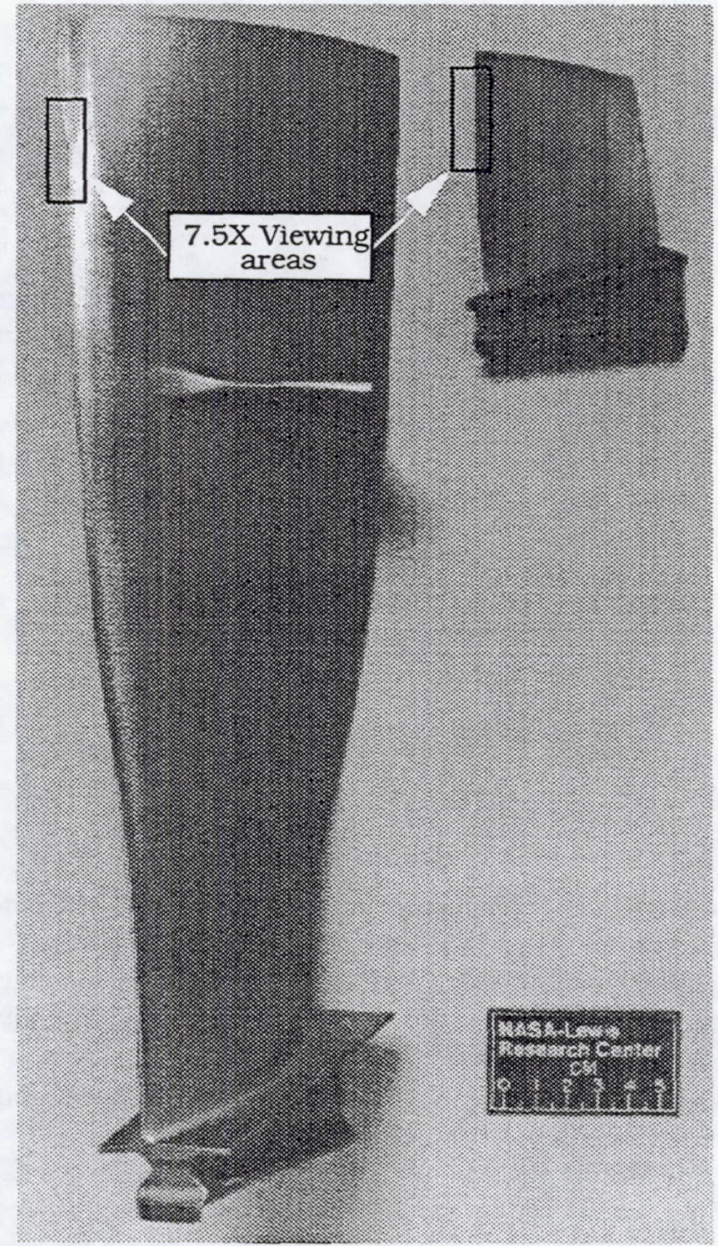

FIGURE 1a. COMPARISON BETWEEN ENGINE FAN BLADE AND THE RESEARCH ROTOR BLADE

while the research rotor leading edge is not pitted. The coatings applied to the research rotor were much softer than the blade itself and did suffer impact damage at the leading edge during testing. However, we did not measure nor did we attempt to control the level of this impact damage. Second, in-service damage generates surface roughness by removing material from the blade while in this investigation we are creating surface roughness by adding material to the blade. In drawing conclusions on inservice performance deterioration based on the results presented herein, one must therefore assume that performance deterioration is dependent on the roughness level but is independent of how the roughness was created.

Both smooth and rough paint coatings were applied to the entire blade surface in an attempt to separate the effects due to adding thickness to the blade from those due to adding surface roughness to the blade. Both coatings were then applied to different portions of the blade surface to determine which portions of the airfoil were most sensitive to thickness/roughness variations. Aerodynamic performance measurements are presented for a number of smooth and rough coating configurations at $60 \%$, $80 \%$, and $100 \%$ of design speed to quantify the performance sen- 


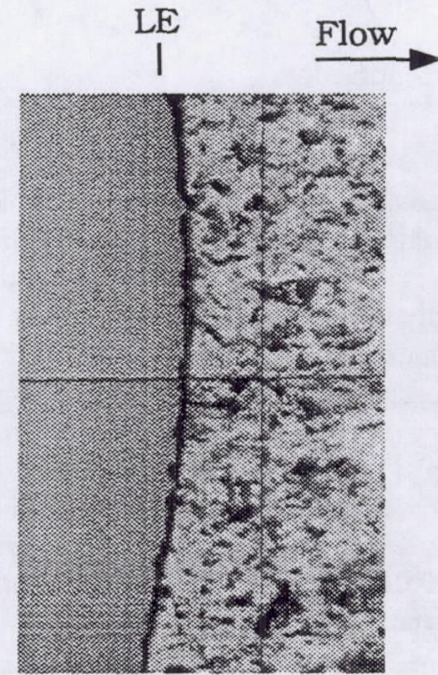

Engine fan blade
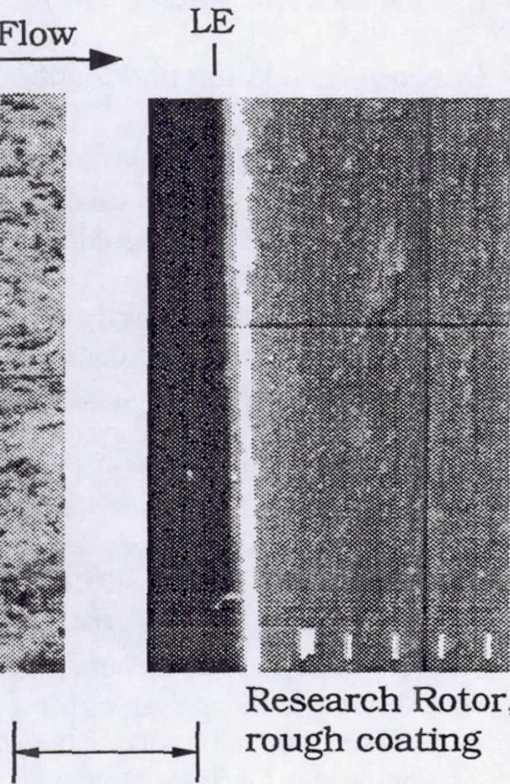

Research Rotor, rough coating

$2.54 \mathrm{~mm}$

(0.1 inches)

FIGURE 1b. 7.5X VIEW OF FAN BLADE AND COATED RESEARCH ROTOR LEADING EDGES

sitivity to thickness and roughness variations over a wide range of operating conditions.

The largest degradation in performance occurred at the design speed operating condition when the entire blade surface was coated. As a result, the baseline (bare metal) rotor, full-coverage smooth coating, and full-coverage rough coating cases were selected for further investigation. Detailed laser fringe anemometer (LFA) measurements were acquired at design speed for these three cases. LFA measurements were acquired upstream, within, and downstream of the blade.

Flow field predictions generated with a quasi-3D Navier-Stokes flow solver were used to complement the LFA measurements by providing insight into the flow development in regions near the blade leading edge and near the blade surface where LFA data could not be acquired. The viscous analysis code featured a $\mathrm{C}$-grid for accurate resolution of the leading edge region and included a surface roughness model. Analysis was performed on the baseline blade, on a blade profile with added thickness with and without added roughness, and on a blade profile with a noncircular leading edge.

\section{TEST COMPRESSOR}

The test compressor for the present study is a low aspect ratio transonic core compressor inlet stage, designated as NASA Stage 37. The results reported here were obtained from a rotor-only configuration with the stator removed. This configuration eliminates blade row interactions and thus allows comparison of the

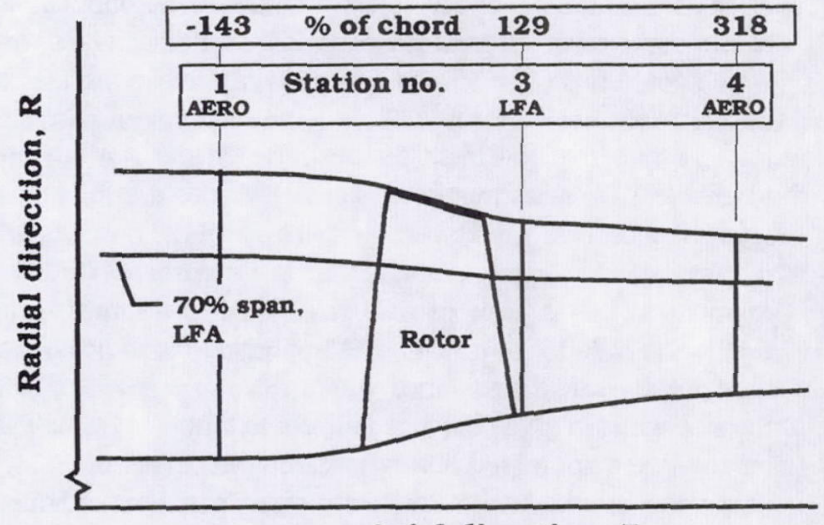

Axial direction, $\mathrm{Z}$

FIGURE 2. LASER ANEMOMETER AND AERODYNAMIC SURVEY STATIONS

measurements with numerical predictions based on circumferentially uniform upstream and downstream conditions.

The rotor design pressure ratio is 2.106 at a mass flow of 20.19 $\mathrm{kg} / \mathrm{s}$. The inlet relative Mach number is 1.13 at the hub and 1.48 at the tip at the design tip speed of $454 \mathrm{~m} / \mathrm{sec}$. The rotor aspect ratio is 1.19 and the hub/tip radius ratio is 0.70 . The rotor tip clearance at design speed is $0.40 \mathrm{~mm}$ ( $0.016 \mathrm{in}$.), which corresponds to $0.7 \%$ of chord. Details of the rotor aerodynamic design were reported by Reid and Moore (1978). Overall aerodynamic performance of the stage was reported by Moore and Reid (1980).

\section{INSTRUMENTATION AND MEASUREMENT TECHNIQUES}

Massflow is measured using a calibrated orifice located far upstream of the compressor. The orifice measurements are corrected to standard-day conditions at the rotor inlet. Radial distributions of total and static pressure, total temperature, and flow angle are measured at stations 1 and 4 shown in Figure 2. Stage 37 is a close-coupled stage, and there is not sufficient space for a survey station between the rotor and stator. Since additional survey stations were not added in the present work, Station 4, which is normally used to survey the stator outlet flow, is the first available aerodynamic survey station downstream of the rotor. The measurement uncertainties are: massflow, $\pm 0.3 \mathrm{~kg} / \mathrm{s}$; flow an gle, \pm 0.5 degrees; total pressure, $\pm 0.01 \mathrm{~N} / \mathrm{cm}^{2}$; total temperature, $\pm 0.6 \mathrm{~K}$. The probe measurements are corrected for Mach number and streamline slope based on a calibration of each probe used and on the design streamline slope. All measurements are corrected to sea-level standard-day conditions at the rotor inlet. Radial distributions of total temperature are mass averaged across the annulus. Radial distributions of total pressure are energy averaged by converting them to their enthalpy equivalents and then mass averaging them across the annulus.

A laser fringe anemometer system (LFA) is used to obtain detailed flow field velocity measurements. This instrument is a twochannel system configured to provide simultaneous measurements 
of the axial and tangential velocity components. Optical access to the compressor is provided by a 2.5 -mm-thick glass window which conforms to the shroud contour, thus preserving the proper tip clearance over the rotor. Polystyrene latex seed particles are injected into the flow field far upstream of the test compressor to enable LFA measurements. These particles are manufactured using the process developed by Nichols (1987) and their size is determined using scanning electron microscope (SEM) photographs. The range of particle sizes used in the present investigation is $0.7-0.9 \mu \mathrm{m}$. The SEM photographs indicate that although the particle size varies within this range between batches, the size within a given batch is uniform to within $0.1 \mu \mathrm{m}$. Particle batches were not mixed during research runs. Therefore, all LFA data were acquired with uniformly sized particles, although the mean particle size varied between $0.7-0.9 \mu \mathrm{m}$. The error in the LFA measurements is approximately $1 \mathrm{~m} / \mathrm{sec}$ for absolute velocity and 0.5 degrees for absolute flow angle and is independent of the particle size over the size range used. Further details concerning the LFA system and measurement technique are reported by Suder and Celestina (1994).

LFA data were acquired from hub to tip downstream of the rotor at Station 3, shown in Figure 2 to provide an assessment of roughness/thickness effects at a location close to the rotor trailing edge. LFA data was also acquired on the blade-to-blade streamsurface at $70 \%$ span shown in Figure 2. The choice of the $70 \%$ span location was driven by several factors. First, aerodynamic performance measurements acquired for the coated blade indicated that at design speed the degradation in pressure and temperature rise was largest near the tip of the blade. Second, previous LFA data acquired in this rotor indicated the tip clearance flow penetrates to at least $90 \%$ span, causing a steep gradient in flow properties across the outer $10 \%$ of blade span. Finally, LFA data had already been acquired for the baseline blade at $70 \%$ span during previous testing of this rotor. The $70 \%$ span streamsurface was therefore chosen as a compromise between our desire to survey the flow field near the tip of the blade and our desire to survey the flow field at a spanwise location at which radial gradients in flow properties were not too strong.

Measurements within the blade were acquired at axial intervals of 5\% chord. At each axial/radial measurement location, data were acquired across all 36 blade passages at a circumferential resolution of 184 points across one blade pitch. All LFA results presented in this paper represent the flow field within an averaged blade passage which was calculated by ensemble-averaging the measurements acquired in each individual blade passage.

The relative Mach number is calculated from the relative velocity and the local speed of sound at each point in the flow field using the procedure discussed by Strazisar et al. (1989). All Mach numbers presented in this report are "2D" Mach numbers in that they are calculated ignoring the radial velocity component, which cannot be measured by the LFA system. Suder and Celestina (1994) have calculated the Mach numbers in rotor 37 with and without the radial velocity component using a 3D Navier-Stokes flow field solution and found that ignoring the radial velocity component led to a maximum error of $2 \%$ in relative Mach number.

\section{EXPERIMENTAL PROCEDURE}

\section{Coating Application and Inspection}

All coatings used in this investigation were applied to the blade surface with a brush using spanwise brush strokes, which provided a uniform coating thickness around the blade leading edge. Chordwise brush strokes were not used since they tended to scrape paint from the brush onto the leading edge, resulting in poor control of the coating thickness at the leading edge. When only part of the blade was coated, a template was used to insure that all blades were painted over a given chordwise area from hub-to-tip. A flat aluminum plate was coated with the same paint using the same brush that was used on the blades and the paint film thickness was measured using a micrometer. The paint thickness on the test plate varied from $0.017 \mathrm{~mm}(0.0007$ in.) to $0.030 \mathrm{~mm}$ (0.0012 in.) for both rough and smooth coatings.

At the conclusion of the test program, several blades painted with the rough coating were inspected in an eyelash machine to determine the uniformity of the coating on the actual blades. After inspecting a painted blade, the paint was removed while the blade was mounted in the eyelash machine and the blade was reinspected, thus providing back-to-back inspections to determine the in-situ coating thickness. The eyelash inspections indicated that the paint film on the blade surface ranged in thickness from $0.013-0.025 \mathrm{~mm}(0.0005-0.0010 \mathrm{in})$. The ability of the eyelash machine to accurately measure the painted blade was assessed by painting a gauge block and determining the paint thickness using a micrometer, an optical comparator, and the eyelash machine. The accuracy of each measurement technique and the coating thickness measured with each technique are shown in Table 1.

TABLE 1 COMPARISON OF COATING THICKNESS AS MEASURED BY VARIOUS TECHNIQUES

\begin{tabular}{|c|c|c|c|c|}
\hline $\begin{array}{c}\text { Meas. } \\
\text { Method }\end{array}$ & \multirow{2}{*}{$\begin{array}{c}\text { Accuracy } \\
\text { mm } \\
(\text { in.) }\end{array}$} & \multicolumn{3}{|c|}{$\begin{array}{c}\text { Gauge block paint thickness, mm } \\
\text { (inches) }\end{array}$} \\
\cline { 3 - 5 } & Minimum & Maximum & Average \\
\hline Micrometer & $\begin{array}{c}0.005 \\
(0.0002)\end{array}$ & $\begin{array}{c}0.028 \\
(0.0011)\end{array}$ & $\begin{array}{c}0.064 \\
(0.0025)\end{array}$ & $\begin{array}{c}0.046 \\
(0.0018)\end{array}$ \\
\hline Comparator & $\begin{array}{c}0.012 \\
(0.0005)\end{array}$ & $\begin{array}{c}0.041 \\
(0.0016)\end{array}$ & $\begin{array}{c}0.043 \\
(0.0017)\end{array}$ & $\begin{array}{c}0.042 \\
(0.0016)\end{array}$ \\
\hline Eyelash & $\begin{array}{c}0.025 \\
\text { machine }\end{array}$ & $\begin{array}{c}0.025 \\
(0.001)\end{array}$ & $\begin{array}{c}0.051 \\
(0.001)\end{array}$ & $\begin{array}{c}0.038 \\
(0.0015)\end{array}$ \\
\hline
\end{tabular}

Note that the average micrometer reading was high compared to that of the comparator and that the eyelash machine was performing at the limits of its resolution. Based on this calibration exercise, the test plate inspections, and the blade eyelash inspections, we conclude that the coating thickness on each surface of the blade was nominally $0.025 \mathrm{~mm}(0.001 \mathrm{in}$.) and was certainly no greater than $0.050 \mathrm{~mm}$ ( $0.002 \mathrm{in})$. A coating thickness of 0.025 $\mathrm{mm}$ on the blade pressure and suction surface corresponds to $10 \%$ of the leading edge thickness at the hub, to $20 \%$ of the leading edge thickness at the tip, and to only $0.3 \%$ of the throat width at the blade tip. Furthermore, the amount of thickness added to the 


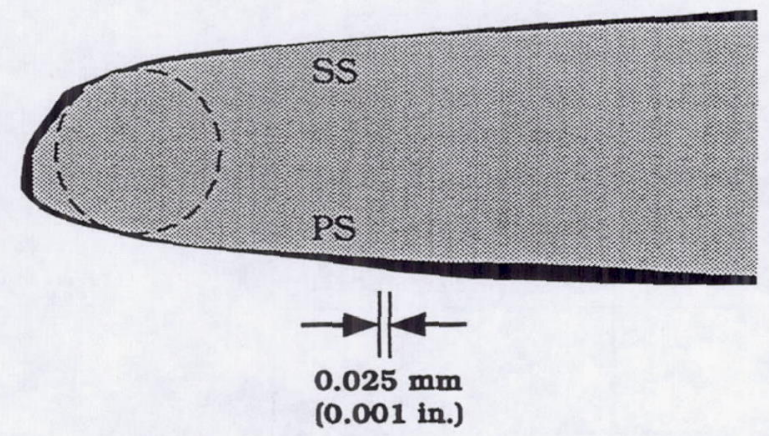

FIGURE 3. EYELASH INSPECTION RESULTS FOR A ROUGHCOATED BLADE AT $90 \%$ SPAN. SUCTION SURFACE, SS; PRESSURE SURFACE, PS

blade surfaces by the coatings was well within the overall blade thickness manufacturing tolerance of $\pm 0.125 \mathrm{~mm}(0.005 \mathrm{in}$.), and is comparable to the leading edge blade thickness manufacturing tolerance of $\pm 0.050 \mathrm{~mm}$ (0.002 in.).

The results of the eyelash inspection for a single blade at $90 \%$ span coated with rough paint are shown in Figure 3. A circle of arbitrary diameter has been fit to the blade leading edge simply to help gauge the degree to which the leading edge is not circular. For this blade at this radius the coating actually tends to make the leading edge more circular than it is for the bare metal blade. The figure also shows that a relatively sharp shoulder exists for both the smooth and coated blade where the leading edge blends into the suction surface. The impact of such a shoulder on the flow development along the blade was investigated computationally, and the results will be discussed later.

The nominal RMS surface finishes determined with a profilometer are shown in Table 2. Also listed in the table are surface finish readings from the engine fan blade shown in Figure 1 and the equivalent roughness Reynolds numbers for the Rotor 37 surface finishes, calculated following the method of Koch and Smith (1975). According to Koch and Smith, the blade surface is considered hydraulically smooth for roughness Reynolds numbers less than 90 .

TABLE 2 RMS SURFACE FINISHES FOR ENGINE FAN BLADE AND ROTOR 37 BLADE

\begin{tabular}{|c|c|c|c|}
\hline Configuration & \multicolumn{2}{|c|}{ RMS surface finish } & $\begin{array}{c}\text { Equivalent sand } \\
\text { roughness } \\
\text { Reynolds No. }\end{array}$ \\
\cline { 2 - 4 } & microns & $\mu$ in. & 93 \\
\hline $\begin{array}{c}\text { Rotor 37, } \\
\text { baseline blade }\end{array}$ & 0.508 & 20 & $47-93$ \\
\hline $\begin{array}{c}\text { Rotor 37, } \\
\text { smooth coating }\end{array}$ & $0.254-0.508$ & $10-20$ & $470-580$ \\
\hline $\begin{array}{c}\text { Rotor 37, } \\
\text { rough coating }\end{array}$ & $2.54-3.18$ & $100-125$ &.--- \\
\hline $\begin{array}{c}\text { fan blade, } \\
\text { pressure surface }\end{array}$ & $4.31-6.10$ & $170-240$ &.-- \\
\hline $\begin{array}{c}\text { fan blade, } \\
\text { suction surface }\end{array}$ & $1.14-1.65$ & $45-65$ & \\
\hline
\end{tabular}

\section{Aerodynamic Performance Measurements}

Aerodynamic performance measurements were acquired for the baseline and fully-coated configurations at 60,80 , and $100 \%$ of design speed. The relative inlet Mach numbers for each speed are:

TABLE 3 ROTOR 37 INLET RELATIVE MACH NUMBERS

\begin{tabular}{|c|c|c|}
\hline$\%$ speed & $\mathrm{M}_{\text {rel }}$ at hub & $\mathrm{M}_{\text {rel }}$ at tip \\
\hline 60 & 0.68 & 0.89 \\
\hline 80 & 0.90 & 1.18 \\
\hline 100 & 1.13 & 1.48 \\
\hline
\end{tabular}

These three speeds were chosen to investigate the correlation between Mach number and performance deterioration due to roughness/thickness. At design speed the relative flow is supersonic from hub to tip. At $80 \%$ of design speed the relative flow is transonic, which is typical of low hub/tip ratio fans. At $60 \%$ of design speed, the relative flow is subsonic everywhere, which is more characteristic of middle- and exit-stage core compressor blading.

The coating configurations and the measurements acquired for each configuration are summarized in Table 4. The column labelled "coating configuration" summarizes the area of the suction and pressure surface (denoted as ss and ps respectively) which was coated. For example, case D featured a coating which was applied from 2-10\% chord on both the pressure and suction surface. Case A corresponds to a single coat of smooth paint, with a nominal thickness of $0.0125 \mathrm{~mm}(0.0005 \mathrm{in}$.). The nominal coating thickness for all other cases is $0.025 \mathrm{~mm}$ ( $0.001 \mathrm{in}$.).

Aerodynamic performance measurements were first acquired for the bare metal rotor at 60,80 , and $100 \%$ of design speed to establish baseline aerodynamic performance. The blades were then coated over their entire surface with the rough paint (case I) and the aerodynamic measurements were repeated to document performance degradation. The coating was then removed using a solvent and wire brush, and the aerodynamic performance measurements on the bare metal blade were repeated. These measurements agreed with the baseline performance measurements

TABLE 4 SUMMARY OF COATING CONFIGURATIONS AND AERODYNAMIC SURVEY CONDITIONS.

\begin{tabular}{|c|c|c|c|c|}
\hline \multirow{2}{*}{ I.D. } & \multicolumn{2}{|c|}{ Coating configuration } & \multirow{2}{*}{\begin{tabular}{c} 
Coating \\
type \\
\cline { 2 - 3 }
\end{tabular} $\begin{array}{c}\text { ps } \\
\text { \%chord })\end{array}$} & $\begin{array}{c}\text { Speed } \\
\text { surveyed } \\
(\% \text { design })\end{array}$ \\
\hline A & $0-100$ & $0-100$ & $\begin{array}{c}\text { smooth } \\
(1 / 2 \text { thick })\end{array}$ & $60,80,100$ \\
\hline B & $0-100$ & $0-100$ & smooth & $60,80,100$ \\
\hline C & $0-10$ & $0-10$ & smooth & 100 \\
\hline D & $2-10$ & $2-10$ & rough & 100 \\
\hline E & --- & $20-30$ & rough & 100 \\
\hline F & $2-100$ & $55-100$ & rough & 100 \\
\hline G & $0-10$ & $0-10$ & rough & 100 \\
\hline H & $0-10$ & $0-50$ & rough & 100 \\
\hline I & $0-100$ & $0-100$ & rough & $60,80,100$ \\
\hline
\end{tabular}




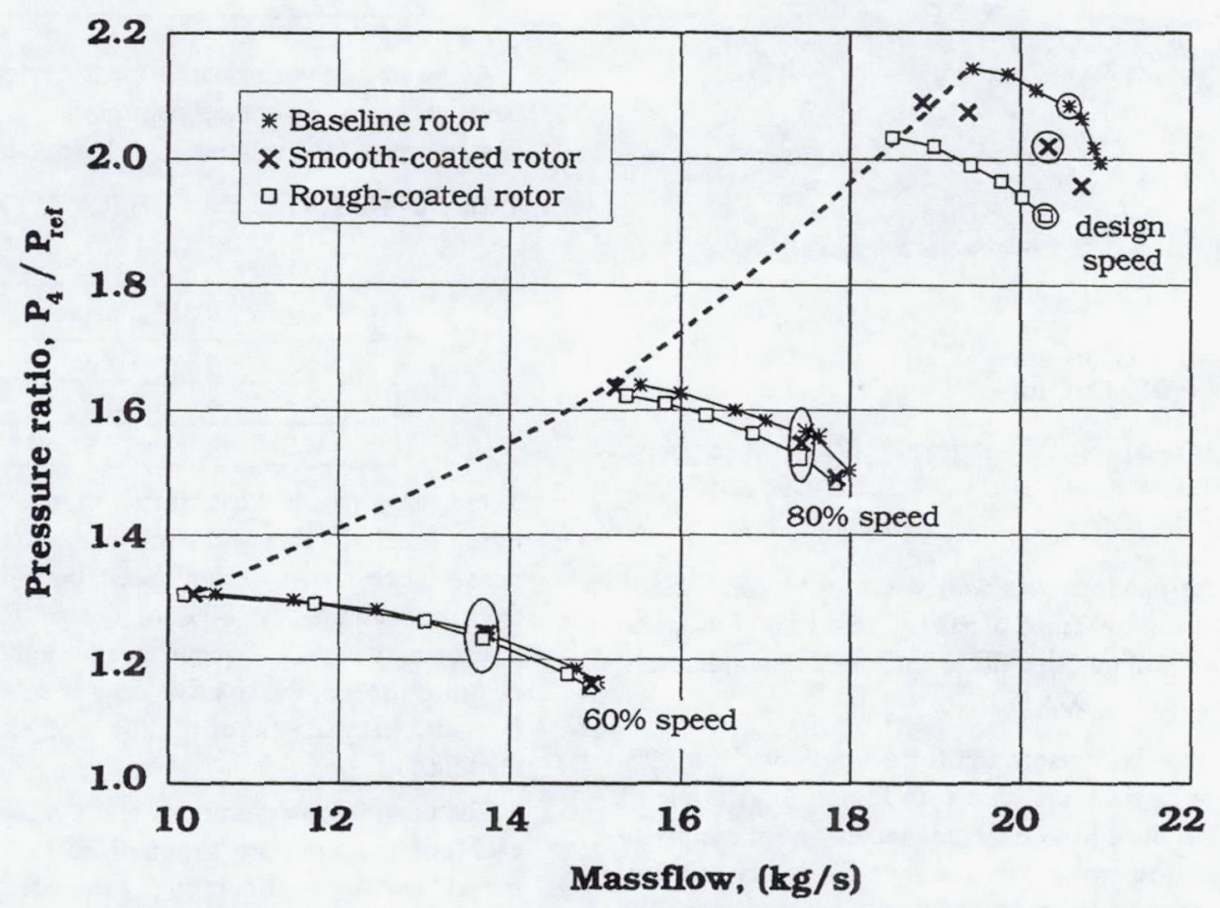

FIGURE 4. PRESSURE RISE CHARACTERISTICS FOR FULL- COVERAGE COATINGS. CIRCLED POINTS INDICATE OPERATING CONDITIONS FOR WHICH RADIAL DISTRIBUTIONS OF FLOW PROPERTIES ARE PRESENTED

to within measurement accuracy, thus verifying that the process of applying and removing the rough coating had not altered the rotor performance.

By applying a rough coating to the blade we added both thickness and surface roughness to the baseline blade. To separate the effects due to thickness from those due to surface roughness, a smooth coating of polyurethane was applied over the entire blade, thereby adding thickness without adding roughness. It was found that two coats of polyurethane were required to develop a coating thickness which was equal to that of the rough paint. Aerodynamic performance measurements were obtained at 60,80 , and $100 \%$ of design speed for both a single coating of polyurethane (case A) and a double coating (case B). At the completion of these measurements the blade was once again cleaned and the baseline aerodynamic performance was once again verified.

To determine which regions of the blade surface contributed most to the observed performance degradation, additional measurements were acquired for a number of partially-coated configurations (cases $\mathrm{C}$ through $\mathrm{H}$ ). All partially-coated configurations were investigated only at design speed, since the performance degradation at design speed for the fully-coated blade was much larger than the degradation observed at part speed conditions. After measurements were completed on each configuration, the blade was cleaned and the baseline aerodynamic performance was spotchecked for repeatability at several points along the design speed operating line.

\section{AERODYNAMIC PERFORMANCE RESULTS}

\section{Fully Coated Configurations}

The smooth- and rough-coated performance is compared to the baseline performance in Figures 4 and 5 . The data points which are surrounded by circles in Figure 4 indicate those points for which detailed radial distributions of flow properties will be discussed below. These results raise a question as to whether the degradation scales with tip speed. To address this issue, we normalized the pressure rise with tip speed and plotted this quantity against massflow. The results, which are not shown here, also indicated a significantly larger degradation at design speed than at part speed conditions. Therefore, neither pressure ratio nor pressure rise scale with tip speed. This indicates that the rotor shock system, which generates much of the pressure rise at design speed, plays an important role in the degradation in pressure rise capability at design speed.

The stall line is not affected by coating the blades, but the maximum massflow achieved by the coated rotor is lower than that of the baseline rotor at all speeds. However, at design speed the highest massflows presented in Figure 4 correspond to choking of the facility diffuser located between the rotor and the throttle valve, rather than choking of the rotor itself. Diffuser choke occurred prior to rotor choke because the diffuser was designed to accept the axial outflow of stage 37 rather than the swirling outflow of rotor 37 . Subsequent testing with the stator in place, 


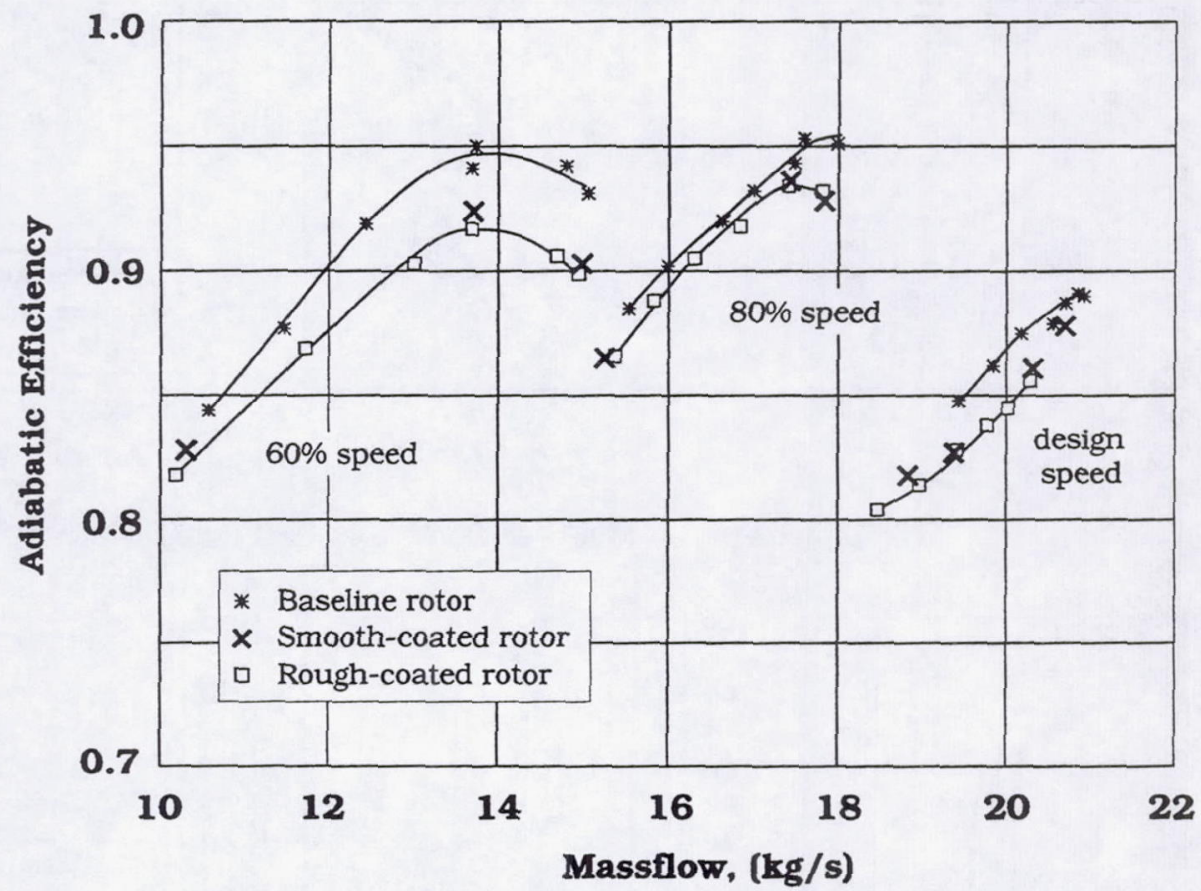

FIGURE 5. EFFICIENCY CHARACTERISTICS FOR FULL-COVERAGE COATINGS

which removes the rotor outlet flow swirl before the flow enters the diffuser, has verified that the isolated rotor configuration was choked at $60 \%$ and $80 \%$ speed but was not choked at design speed.

The results shown in Figure 5 indicate that for a given massflow the efficiency penalty for the coated rotor configurations is on the order of 1-3 points at $60 \%$ speed, $0.5-1$ points at $80 \%$ speed, and 2.5 points at design speed. Note that the efficiency penalty at design speed is not much larger than that at $60 \%$ speed. In addition, the efficiency levels measured for the smooth and rough coatings are nearly identical. This fact suggests that the efficiency is adversely impacted by the addition of thickness alone, and that the surface roughness level used in the present investigation does not have an appreciable impact on efficiency. However, this conclusion is misleading since both the pressure ratio and efficiency are changing.

A clearer view of the efficiency changes at design speed is shown by plotting efficiency against pressure ratio, as shown in Figure 6 . With both efficiency and pressure ratio changing appreciably, it seems appropriate to assess the efficiency penalty for both a constant pressure rise and a constant throttle resistance. For a constant pressure rise, the efficiency loss is on the order of 2.5-3.5 points for the smooth coating and 6-8.5 points for the rough coating. These loss levels would be experienced in compressor applications which require a constant pressure rise, such as pipeline pumping and stationary power generation. In contrast, aircraft engine fans and compressors operate against a fixed throttle resistance, and the operating point will move along a constant-throttle line as the compressor deteriorates in service. An approximate throttle line is shown in Figure 6. The efficiency loss along this line is 3.5 points for the smooth coating and 6 points for the rough coating.

Figure 7 illustrates the spanwise variation of pressure ratio, temperature ratio, and adiabatic efficiency for the circled operating points shown in Figure 4. The massflow chosen for comparison of the baseline and coated configurations at 60 and $80 \%$ speed corresponds to the peak efficiency massflow for the baseline rotor. At design speed, the massflow chosen corresponds to the maximum massflow achieved by the rough-coated rotor. Note that by comparing the baseline and coated blade performance at a constant massflow for each speed, we are maintaining a constant incidence angle for the performance comparison at a given speed.

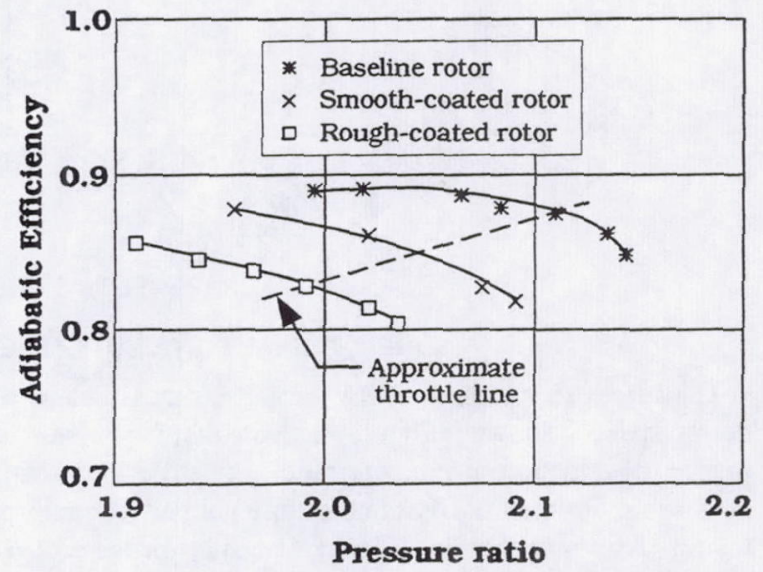

FIGURE 6. EFFICIENCY-PRESSURE RATIO CHARACTERISTICS AT DESIGN SPEED 

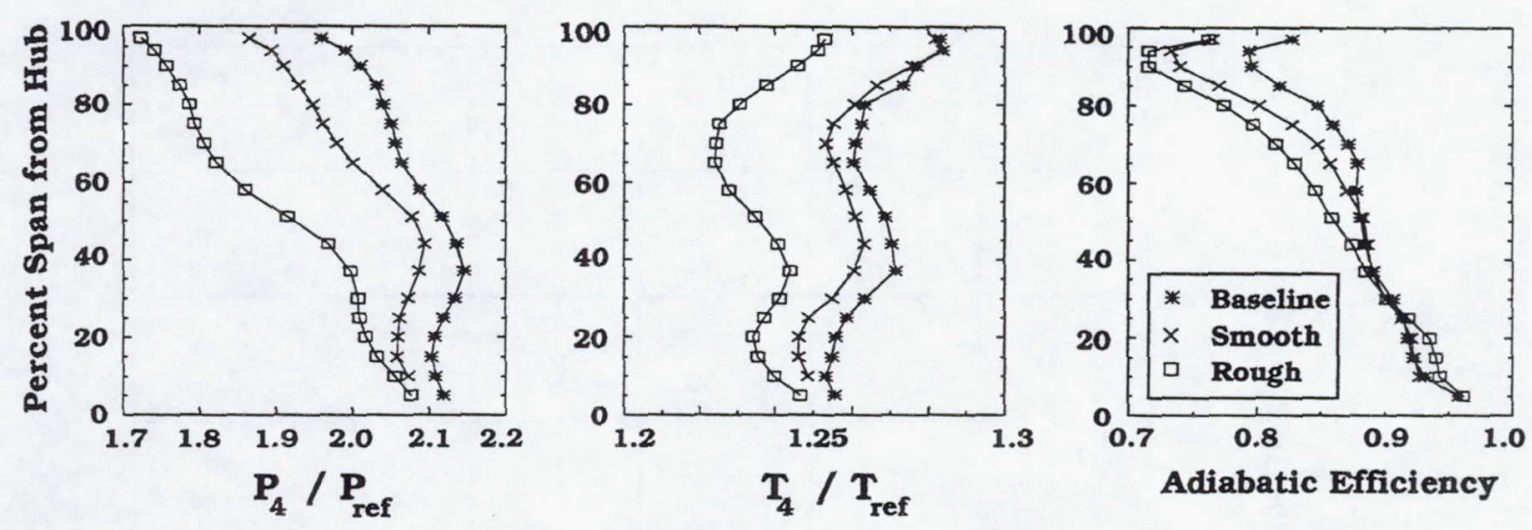

(A) $100 \%$ SPEED, NEAR PEAK EFFICIENCY, $20.31 \mathrm{KG} / \mathrm{S}$
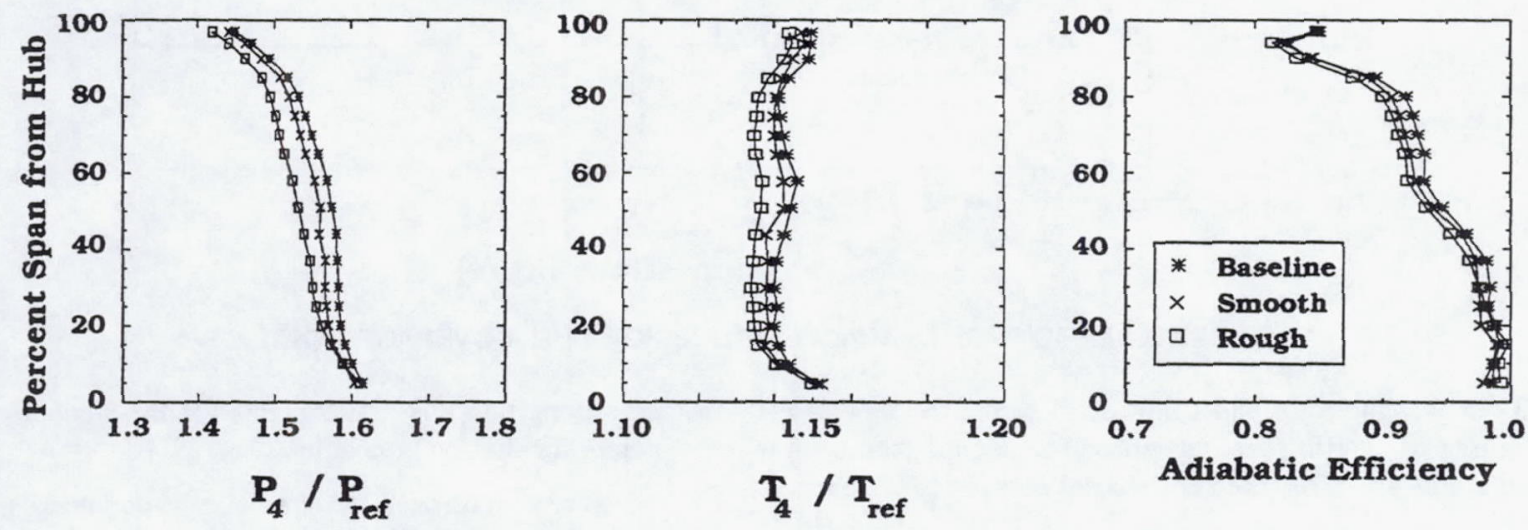

(B) $80 \%$ SPEED, NEAR PEAK EFFICIENCY, $17.44 \mathrm{KG} / \mathrm{S}$
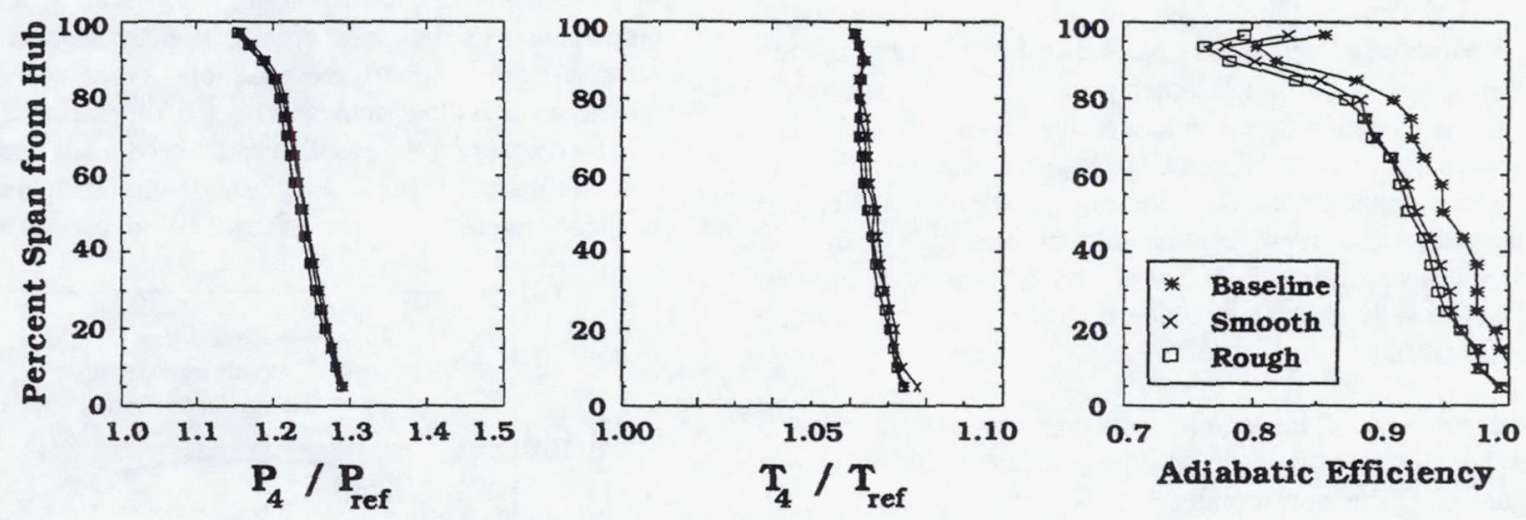

(C) $60 \%$ SPEED, NEAR PEAK EFFICIENCY, $13.71 \mathrm{KG} / \mathrm{S}$

FIGURE 7. RADIAL DISTRIBUTIONS OF PRESSURE RATIO, TEMPERATURE RATIO, AND EFFICIENCY

The spanwise variation of flow properties measured at $100 \%$ of design speed is shown in Figure 7a. Note that for the smooth coating the degradation in pressure ratio is relatively constant below $50 \%$ span, but then nearly doubles in level between midspan and the tip. Also note that the efficiency penalty for the coated blades only becomes appreciable outboard of 40-60\% span. Alber et al. (1973) have shown that for $M_{\text {rel }} \geq 1.4$, the pressure rise through a normal shock is strong enough to cause boundary layer separation. At design speed, the inlet relative Mach number for Rotor 37 varies from 1.13 at the hub to 1.48 at the tip. However, due to expansion along the suction surface, the Mach number at the face of the passage shock is greater than 1.4 outboard of midspan, and a strong shock/boundary layer interaction is therefore possible over the outer half of the blade span. These facts, coupled with 


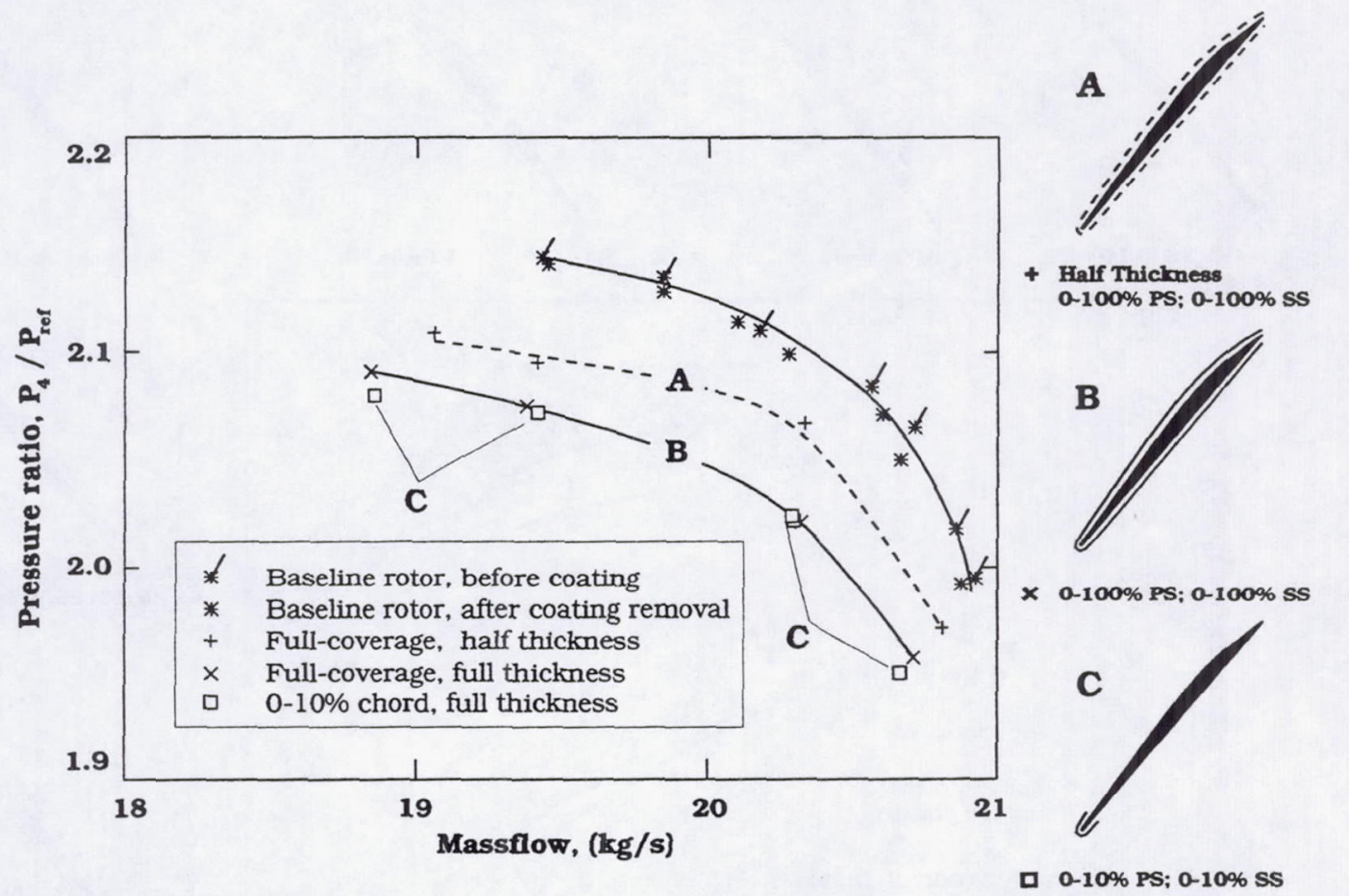

FIGURE 8. PRESSURE RISE CHARACTERISITICS FOR THE SMOOTH COATINGS AT DESIGN SPEED

the results shown in Figure 7a, indicate that the shock boundary layer interaction is an important contributor to the design speed performance degradation. This point is investigated in more detail later in this paper.

The spanwise variation of flow properties at $80 \%$ and $60 \%$ speed is shown in Figures $7 \mathrm{~b}$ and $7 \mathrm{c}$. The rotor shock system is quite weak at $80 \%$ speed and is only present in the outer half of the span. The performance decrement at part speed conditions is much smaller than at design speed and more uniform in magnitude across the span. These results suggest that at lower Mach numbers the coating effect on the blade surface boundary layers is the important flow phenomena and that this effect is much weaker than the shock/boundary layer interaction effects which occur at design speed.

\section{Partially Coated Configurations}

Modern aircraft fans and compressors often operate under supersonic relative flow conditions over part of the blade span. The high Mach number results of the current study are therefore of particular interest. Since the preceding results have shown that the largest deterioration in rotor pressure rise occurs at design speed, we decided to coat various regions of the blade surface with smooth and rough coatings and acquire additional performance measurements at design speed to determine those areas of the blade surface which display the greatest sensitivity to the addition of thickness and roughness.

The results of the partial-coating study are shown in Figures 8 and 9 for the nine coating configurations previously listed in
Table 4. For the baseline performance in both figures, the flagged data points were measured before any coatings were applied, while the unflagged points were measured on several different occasions after removal of coatings. The agreement between the flagged and unflagged points indicates that the baseline blade performance was not affected by the continued application and removal of coatings.

The pressure rise characteristics for the smooth-coated configurations $\mathrm{A}-\mathrm{C}$ are compared to those of the baseline rotor in Figure 8. Coatings $A$ and $B$ are full-coverage coatings with coating $A$ being only half as thick as all other coatings. Coating $\mathrm{C}$ covers only the first $10 \%$ of blade chord. It can be seen that performance for the half thickness coating falls approximately half way between that of the baseline and full thickness coating. However, the most dramatic result in Figure 8 is that the performance deterioration for case $\mathrm{C}$, in which only the leading edge region is coated, is virtually identical to that of case $B$ in which the entire blade is coated. This result indicates that the added blade profile thickness from $10-90 \%$ chord does not contribute to the performance deterioration observed for Case B.

Figure 9 shows the decrease in design speed pressure ratio for rough coating configurations D-I listed in Table 4 . The lowest massfiows shown for cases $\mathrm{G}$ and $\mathrm{H}$ do not reflect the stall massflow - the stall point was simply not determined for these cases. As expected, the full coverage of rough paint, case I, gives the greatest deterioration in performance. This coating was applied on two separate occasions and yielded identical performance characteristics, thereby verifying the repeatability of the hand-application coating process. Case $\mathrm{G}$, in which only the first $10 \%$ of chord is coated, exhibits approximately $70 \%$ of the performance degradation of the full roughness coverage. In case $\mathrm{H}$ the suction surface 

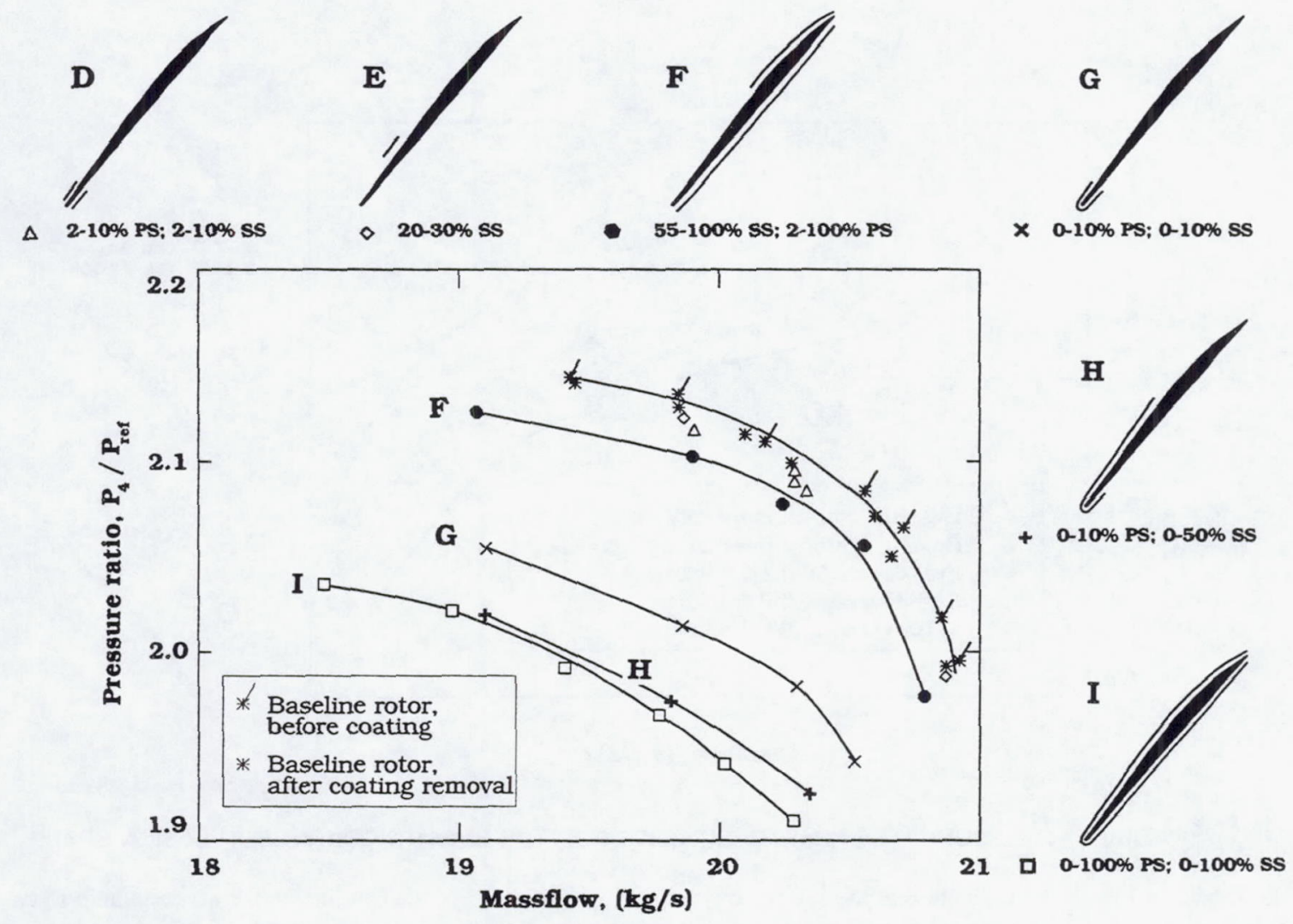

FIGURE 9. PRESSURE RISE CHARACTERISITICS FOR THE ROUGH COATINGS AT DESIGN SPEED

is coated up to the point at which the rotor passage shock impinges on the suction surface, while in case $F$ the suction surface is only coated downstream of this point. Cases $\mathrm{G}, \mathrm{H}$, and I together indicate that the addition of roughness to the blade leading edge and the suction surface up to the point of shock impingement accounts for most of the performance degradation seen for the fully-coated blade.

Cases D, E, and F all feature partial coatings which did not cover the leading edge of the blade. Case $E$ represents an attempt to trip the suction surface boundary layer by adding a strip of roughness in the high Mach number region between 20-30\% chord. This case shows virtually no performance deterioration relative to the baseline blade.

Further discussion of the partial coating results will be easier if we can summarize the information in Figures 8 and 9 in a single, quantitative format. Figure 10 is an attempt at providing such a format. Figure 10 is a summary of the degradation in design speed pressure ratio as a function of the blade surface area covered by the full-thickness smooth and rough coatings. The results are shown for a massflow of $20.3 \mathrm{~kg} / \mathrm{s}$. This massflow is the highest massflow reached for case I in Figure 9, is the massflow used for the comparisons in Figure 7, and is also near the baseline rotor design point massflow of $20.19 \mathrm{~kg} / \mathrm{s}$. The shaded bars represent the coated areas of the blade surface for each case. The plot abscissa represents an "unwrapped" blade surface with the blade leading edge at the center. The plot ordinate is the percent reduction in pressure ratio, defined as

$$
100 * \frac{(P R)_{\text {baseline }}-P R}{(P R)_{\text {baseline }}}
$$

Figure 10 illustrates the magnitude of the performance degradation at a fixed flow rate while Figures 8 and 9 illustrate that the level of degradation is not strongly dependent on the flow rate. The following conclusions for the design speed condition can be drawn from these results:

1. There is little performance degradation when the leading edge is left uncoated (Cases D,E,F).

2. Performance degradation is triggered by additional thickness and/or roughness at the leading edge.

- Cases D and G are geometrically similar except that Case $\mathrm{D}$ has no coating at the leading edge ( $0-2 \%$ chord). Case $\mathrm{G}$ exhibits performance degradation while Case D does not, which suggests that the coating on the first $2 \%$ of chord is the cause of the degradation observed for case G.

- Cases B and C exhibit identical degradation levels even though Case $\mathrm{C}$ is uncoated over much of the blade surface.

- Case G (first $10 \%$ of surface coated) exhibits $70 \%$ of the degradation level of Case I (entire surface coated). 


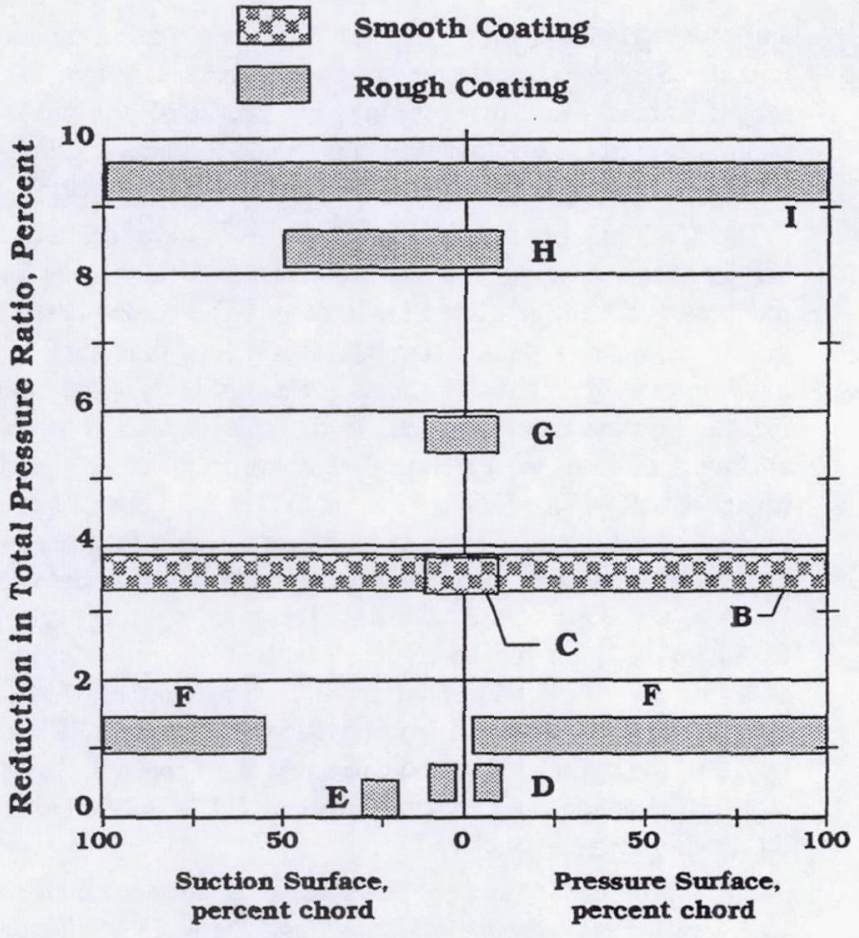

FIGURE 10. PRESSURE RATIO DEGRADATION AS A FUNCTION OF BLADE SURFACE AREA COVERED BY SMOOTH AND ROUGH COATINGS AT DESIGN SPEED, MASSFLOW $=20.3 \mathrm{KG} / \mathrm{S}$

3. Pressure surface roughness has little impact on performance degradation

- Case F, in which the entire pressure surface was coated, demonstrates little degradation.

- There is little difference in degradation between cases $\mathrm{H}$ and I. The pressure surface is completely coated for case $\mathrm{I}$ and is uncoated from $10-100 \%$ chord in Case $\mathrm{H}$.

4. Roughness on the uncovered portion of the suction surface has an impact on performance degradation.

- Cases C (smooth coating) and G (rough coating) are geometrically identical and differ only in the level of roughness, but Case $\mathrm{G}$ displays more performance loss than Case C.

- Cases $\mathrm{G}$ and $\mathrm{H}$ differ only in the extent of the roughness on the suction surface.

The results shown in Figure 10 clearly indicate that the leading edge region plays a critical role in the performance degradation and that coating the leading edge results in performance loss. In coating the leading edge we increased its thickness by $10 \%$ at the hub and by $20 \%$ at the tip. Both the smooth and rough coatings had a lower surface hardness than the bare metal blade. As a result, coating the blade also increased the roughness at the leading edge because the coated blades suffered particle impact damage at the leading edge during testing which was not suffered by the baseline metal blade. We cannot separate the effects due to increased leading edge thickness from those due to increased leading

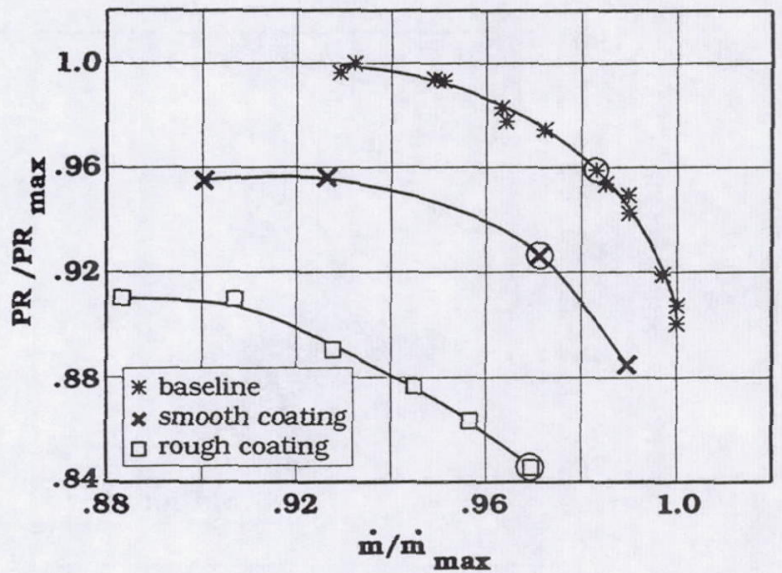

FIGURE 11. PRESSURE RATIO VS MASSFLOW CHARACTERISTICS AT $70 \%$ SPAN. CIRCLED POINTS INDICATE OPERATING CONDITIONS DURING LASER ANEMOMETER SURVEYS

edge roughness based on the measurements alone. However, the numerical analysis presented later in this paper indicates that the observed performance degradation is not a thickness effect.

\section{LASER ANEMOMETER RESULTS}

All LFA data reported herein was acquired at design speed for the baseline blade as well as the full-coverage smooth and rough coating configurations (cases $\mathrm{B}$ and $\mathrm{I}$ ). The pressure ratio vs massflow characteristics for the $70 \%$ span streamsurface for these three cases are shown in Figure 11. The massflow at which LFA data were acquired for each case is shown by the circled symbols. The characteristics are shown for the $70 \%$ span streamsurface to facilitate comparison to the CFD predictions made on the same streamsurface. The massflow and pressure ratio have been normalized by their respective maximum values for the baseline blade for the same reason.

\section{Spanwise Velocity Distributions}

The aerodynamic performance measurements presented above were based on measurements acquired with aerodynamic survey probes at Station 4 (see Figure 2). Since Station 4 was two rotor chords downstream of the trailing edge, there was some concern that mixing which occurs between the rotor trailing edge and Station 4 might cause the aerodynamic measurements to provide an inaccurate view of the effects of roughness/thickness variations on rotor performance. LFA data were therefore acquired at Station 3 , close to the rotor exit, for comparison with the aerodynamic survey measurements obtained far downstream at Station 4 . The measured total temperature rise was chosen for this comparison since it is a measure of the work input across the rotor.

The Euler equation for turbomachinery was used to calculate the radial distribution of total temperature at Station 3 from the LFA velocity measurements. Figure 12 is a comparison between the aerodynamic probe measurements at Station 4 and the pitchaveraged total temperature ratios determined from the LFA measurements at Station 3. Comparison of the temperature distribu- 

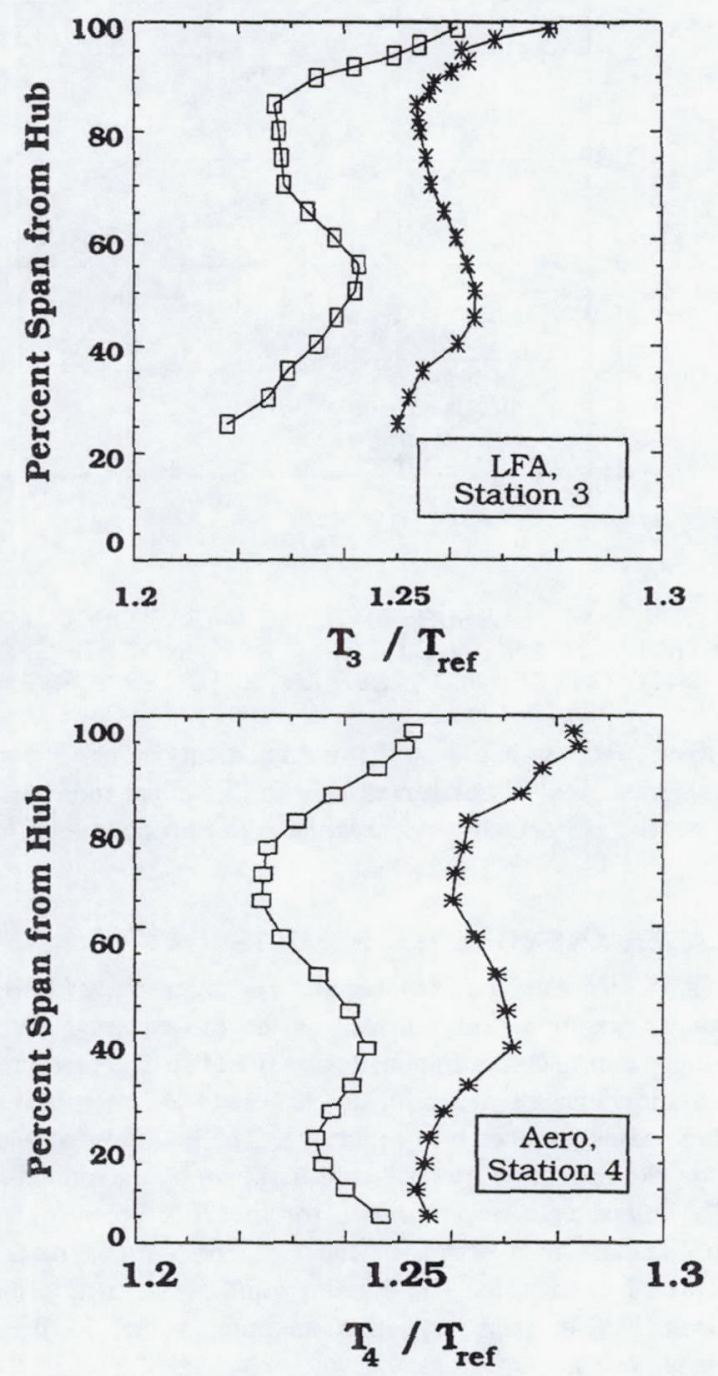

* baseline $\square$ rough coating

FIGURE 12. COMPARISON BETWEEN TEMPERATURE RATIOS MEASURED NEAR THE ROTOR TRAILING EDGE WITH THE LFA AND FAR DOWNSTREAM WITH AERODYNAMIC SURVEY PROBES

tions in Figure 12 indicates that the temperature changes measured by the aerodynamic survey probes at Station 4 are qualitatively similar to those calculated from the LFA measurements near the trailing edge. In both cases the coatings cause a decrease in temperature rise across the entire blade span. The aerodynamic performance measured by the probes at Station 4 is therefore taken to be an accurate representation of the rotor performance.

\section{Blade-to-Blade Flow Details}

Figure 13 illustrates the distribution of local relative Mach number determined from the LFA measurements on the $70 \%$ span streamsurface shown in Figure 2 for the baseline, smooth-coated, and rough- coated blades. The Mach number contour increment is 0.10 . The inset shows the shock location, as defined by the $M_{\text {rel }}=1.3$ contour line, for each case. The $20,40,65,90$, and $115 \%$ chord locations are also noted because blade-to-blade distributions of Mach numbers at these locations will be presented below.

The Mach number distributions upstream of the shock are quite similar except near the blade suction surface, where lower Mach numbers occur in the coated blade cases. The coated cases also display a more prominent lambda shock foot than that of the baseline case. The passage shock angle is slightly more oblique for the baseline case compared to the coated cases, but this is attributed more to the baseline data being acquired at a slightly higher massflow (see Figure 11) than to flow field changes caused by coating the blade. The shock stand-off distance from the blade leading edge appears to be the same for the baseline and coated blade cases. This agrees with data presented by Liepmann and Roshko (1967) on the stand-off distance for circular cylinders as a function of cylinder diameter and Mach number. Although the coatings increased the leading edge thickness at $70 \%$ span by $15 \%$, the cylinder data indicates that the expected change in stand-off distance for a Mach number of 1.4 is only one-half of the leading edge diameter.

The similarities in the flow fields ahead of the shock are consistent with the fact that the massflow, and therefore the incidence angle, are nearly the same for all three cases. Since the shock geometry is similar, the question remains as to why the pressure rise across the rotor varies considerably for these three cases. The pressure rise across the shock accounts for much of the overall pressure rise across the rotor, and the loss in pressure rise for the coated cases must therefore be due to changes in the flow field downstream of the shock. In both coated cases there is a region of low Mach number along the suction surface downstream of the shock impingement point. This behavior is not observed in the baseline blade Mach number distribution. These results indicate that the shock/boundary layer interaction generates a larger region of low momentum fluid near the suction surface in the coated cases.

A more quantitative view of the Mach number differences between the coated and baseline blades is provided by the streamwise Mach number distributions shown in Figure 14, which displays the distribution of Mach number along the mid-pitch line, denoted by A-A. The baseline data is denoted by the * symbols, while the smooth-coated and rough-coated data are denoted by the solid and broken lines respectively. The location and strength of both the bow shock and passage shock are nearly identical for all three cases, providing quantitative evidence that the flow field ahead of the shock and the pressure rise across the shock are not sensitive to the presence of the coatings. The baseline passage shock lies slightly downstream of that for the coated blades, which is consistent with the baseline data being acquired at a slightly higher massflow. The main difference between the three cases shown in Figure 14 is in the levels of reacceleration and subsequent diffusion downstream of the shock. The net result is a higher Mach number at the trailing edge and a decrease in the overall diffusion between the leading edge and trailing edge. This is consistent with the reduced pressure rise observed for the coated cases. 

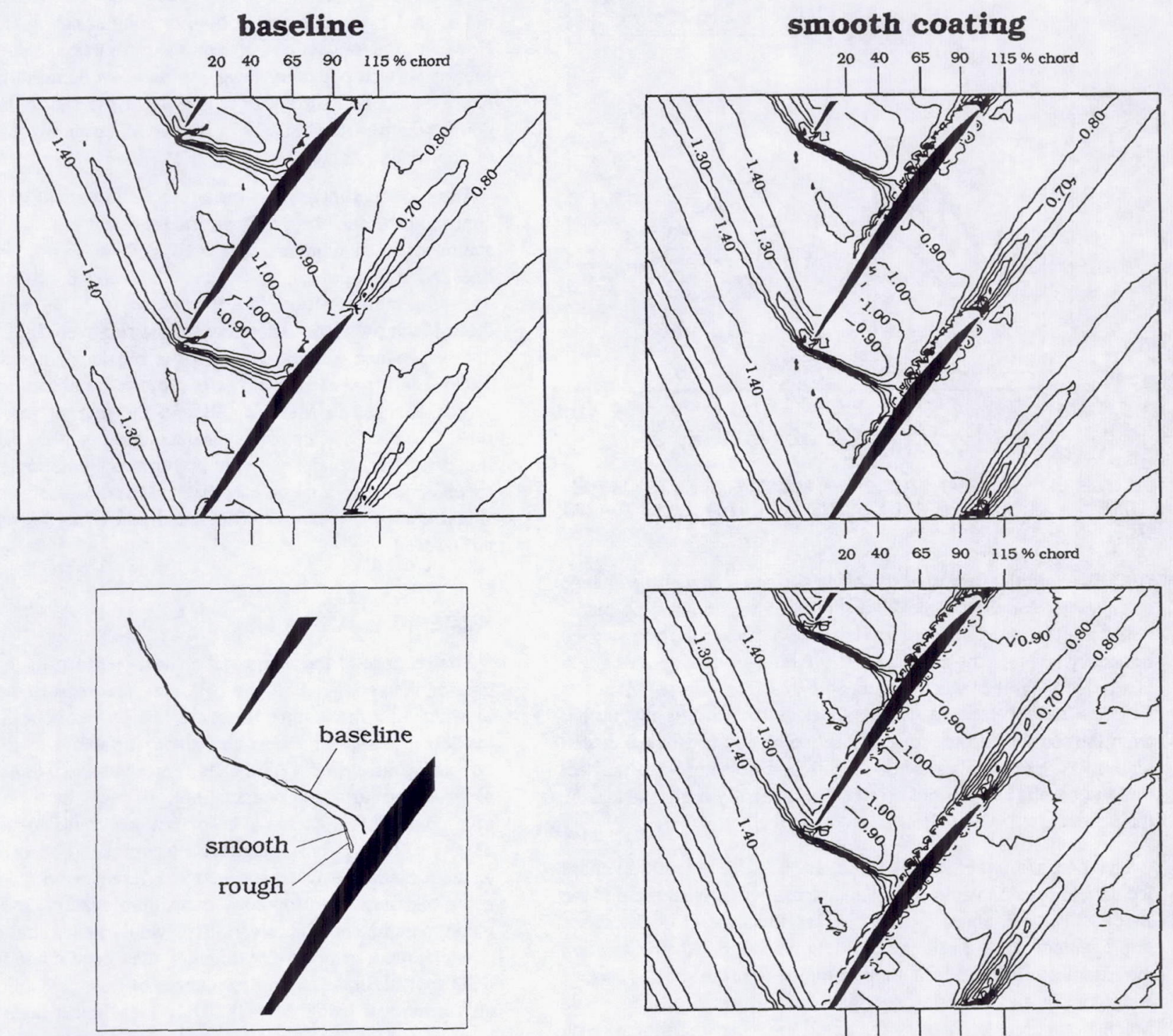

Shock location

$\left(\mathrm{M}_{\mathrm{rel}}=1.3\right.$ contour lines $)$
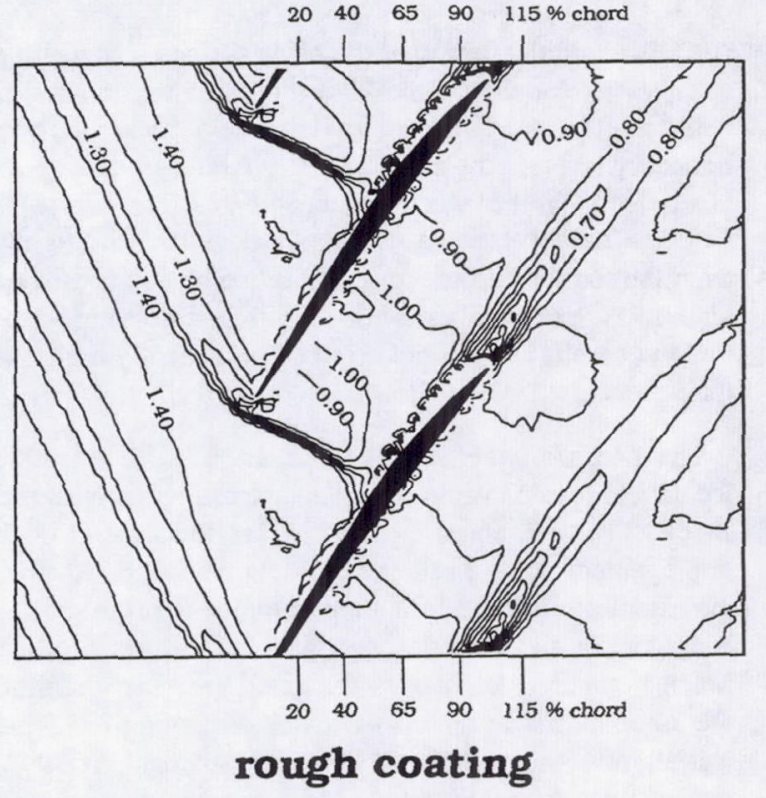

FIGURE 13. LASER ANEMOMETER MEASUREMENTS OF RELATIVE MACH NUMBER ON THE $70 \%$ SPAN STREAMSURFACE

A final comparison of the flow fields in the baseline and coated blades is provided by the blade-to-blade Mach number distributions shown for selected chordwise locations in Figure 15. Note that although the minimum and maximum value of the ordinate scale is different for each chordwise location, the sensitivity of the ordinate scale is uniform throughout the figure ( 1 division $=$ 0.1). The abscissa in each plot in Figure 15 covers one blade pitch. The blade suction surface is on the left and the local blade section thickness is denoted by the cross-hatched region on the right. The LFA measurements are plotted at each of the 184 measurement points across the blade pitch. Regions in which there are no measurements are the result of optical blockage of the laser beam paths due to radial twist in the blade. In particular, the LFA data did not provide any information concerning separation of the suction surface boundary layer in the rear of the rotor because the LFA beams are blocked by the blade for the first $5-8 \%$ of pitch.

The $20 \%$ and $40 \%$ chord locations are upstream of the point at which the passage shock impinges on the blade suction surface. 


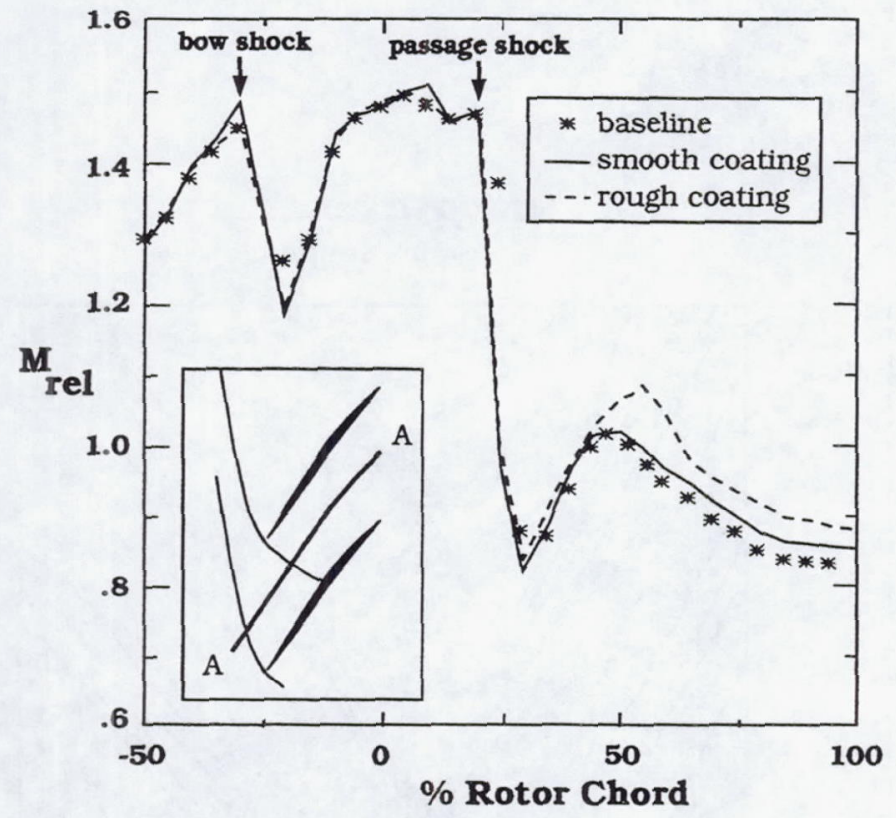

FIGURE 14. LASER ANEMOMETER MEASUREMENTS OF RELATIVE MACH NUMBER ALONG THE MID-PITCH LINE, A-A, AT $70 \%$ SPAN

At $20 \%$ chord the flow near the blade surfaces shows little change in character for the coated blades relative to the baseline blade, while at $40 \%$ chord there is evidence of a thicker suction surface boundary layer on the coated blades. Although the shock strength (as judged by the Mach number change across the shock) is identical for all three cases, the shock is located slightly farther from the suction surface for the baseline blade than for the coated blades. As previously discussed, this is consistent with the fact that the baseline data were acquired at a slightly higher massflow than the coated blade data.

The Mach number distributions at the $65 \%$ and $90 \%$ chord locations provide insight into blockage changes downstream of the shock. The $65 \%$ chord location is just downstream of the shock impingement point on the blade suction surface. At this location the extent of the low Mach number region near the suction surface is larger for the coated cases than for the baseline case. The Mach number levels across the pitch are nearly identical, with the smooth- and rough-coated cases displaying levels which are just slightly above those of the baseline case. At $90 \%$ chord it is clear that the coated blade Mach number distributions display a significantly larger region of low Mach number fluid near the suction surface. Consistent with the increased blockage near the suction surface, the coated blade Mach number levels are higher than those of the baseline case across most of the blade pitch.

The final set of Mach number distributions presented in Figure 15 was acquired at $15 \%$ of blade chord downstream of the trailing edge. This is the first location at which the LFA beam path is completely free from optical blockage by the blade and therefore affords us the first opportunity to obtain LFA data across the entire blade wake. The results indicate a well-behaved increase in freestream Mach number and in wake momentum deficit (and therefore blade profile loss) as we move from the baseline case to the smooth-coated and the rough-coated cases.

In summary, the LFA measurements indicate that the flow field upstream of the rotor passage shock and the shock itself are not altered by adding the smooth or rough coating to the blade. However, the interaction between the rotor passage shock and the suction surface boundary layer results in an increase in blockage along the suction surface downstream of the shock impingement point, which in turn results in higher Mach numbers in the rear of the blade passage.

The blockage increase is the principle flow field change which contributes to the observed performance deterioration. The pitchaveraged Mach numbers measured at $90 \%$ chord for the baseline and rough-coated blades are 0.840 and 0.900 respectively. The area ratio function, $A / A^{*}$, is equal to 1.024 and 1.009 for these Mach numbers. Therefore, at the relatively high exit Mach numbers which exist in Rotor 37 , a blockage increase of only $1.024-1.009=0.015$, or $1.5 \%$, is required to account for the observed changes in Mach number in the rear of the blade passage. The shock/boundary layer interaction is a key factor in this process. This explains why the performance deterioration at partspeed conditions is much less than that at design speed, since the shock is much weaker at $80 \%$ speed and is not present at all at $60 \%$ speed.

\section{NUMERICAL ANALYSIS}

The purpose of the numerical analysis performed in this investigation is to complement the LFA measurements in those regions in which the measurements could not be easily acquired (near the leading edge and near the blade surface) and to provide a qualitative assessment of the flow mechanisms which cause the observed performance degradation. To meet these goals with a minimum of computational resources we chose to use a quasi$3 D$ rather than a full $-3 D$ analysis technique. Use of a quasi-3D technique allowed us to run many different cases while varying blade thickness, grid topology, transition location, and roughness model parameters. These variations would have required an inordinate amount of computer time had they been made while using a 3D analysis code. A limited number of flow field solutions were also generated using the full-3D Navier-Stokes code developed by Dawes (1988). The quasi- and full-3D solutions were compared to insure that there were no qualitative differences in the roughness/thickness effects predicted by the two approaches.

The quasi-3D results are generated using a thin-layer NavierStokes analysis code developed by Chima (1987). The code includes radius change and variable streamtube thickness which were estimated from the flowpath convergence. An explicit fourstage Runge-Kutta time-marching algorithm is used with residual smoothing to improve convergence. The code employs the Baldwin-Lomax algebraic turbulence model (1978). The model is fairly accurate for attached flows, but not as good for shockinduced separation. Transition is modeled by calculating a turbulent viscosity profile along each blade-to-blade grid line, but setting the entire profile to zero if the maximum is less than a constant (usually 14) times the laminar viscosity. The model does not 

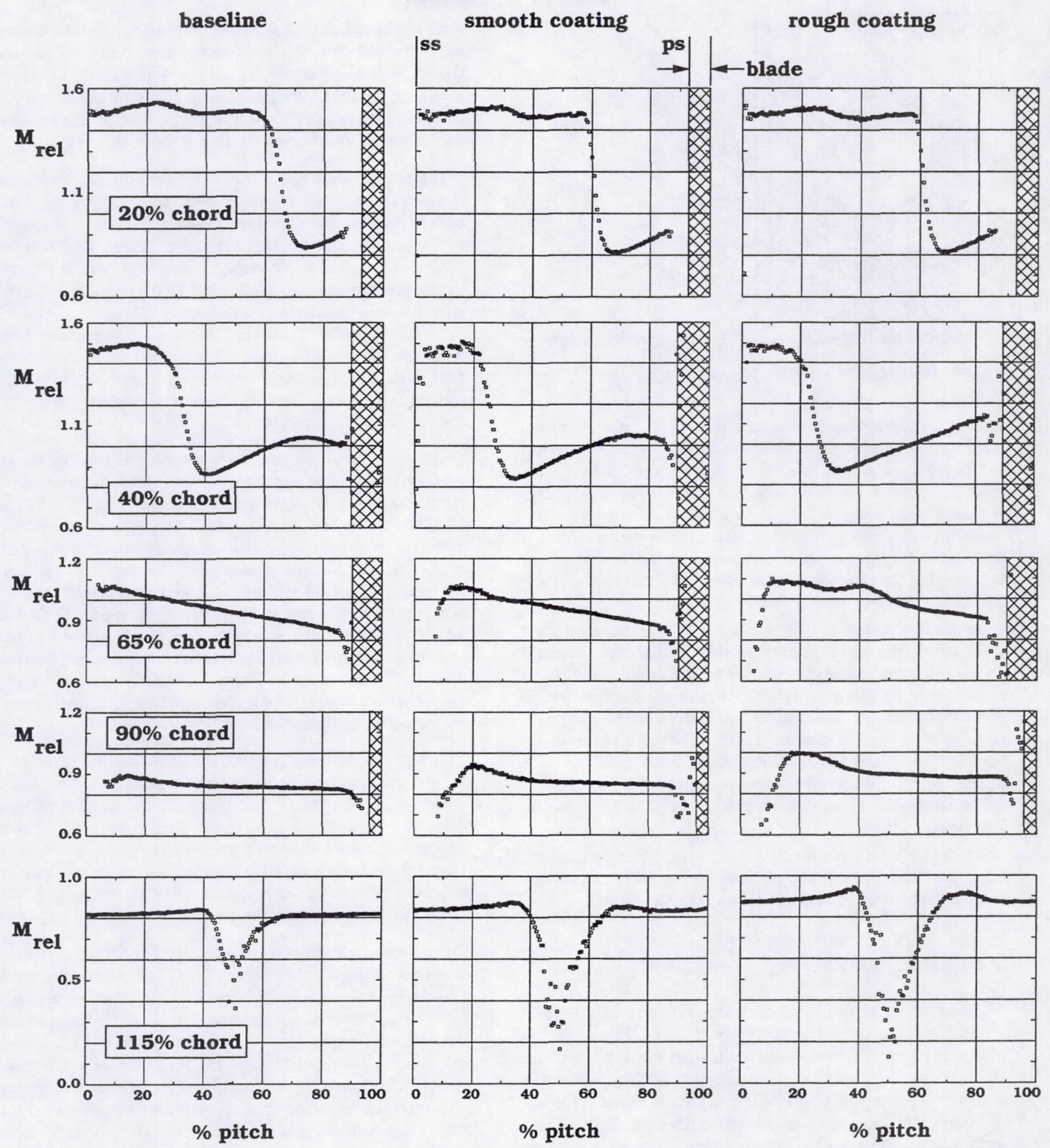

FIGURE 15. LASER ANEMOMETER MEASUREMENTS OF RELATIVE MACH NUMBER ACROSS THE BLADE PITCH ON THE $70 \%$ SPAN STREAMSURFACE 


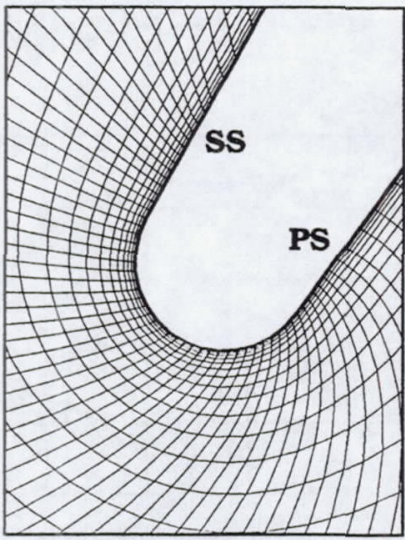

Circular leading edge

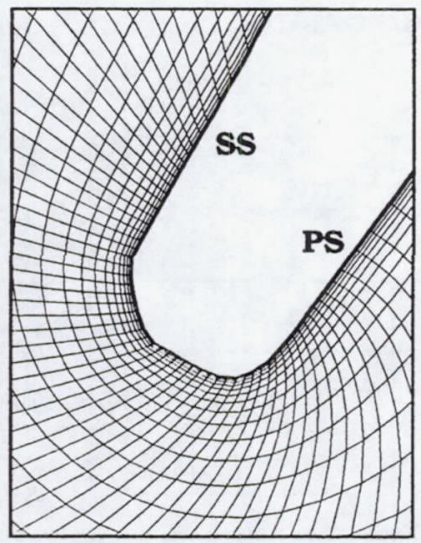

Faceted leading edge
FIGURE 16. CFD GRID DETAIL AT THE LEADING EDGE

account for free-stream turbulence effects. The transition model was proposed in the original Baldwin-Lomax paper but it is not considered to be especially accurate. Surface roughness is modeled by increasing the turbulent mixing length using the approach of Cebeci and Chang (1978). The additional mixing length is a function of the equivalent sand grain roughness height, which is fairly small for the roughness considered here. The addition of this model to the code has been discussed in detail by Boyle and Civinskas (1991) and Boyle (1993).

The blade geometry at $70 \%$ span is used for the baseline blade profile. A C-type grid is used to provide good resolution around the blade leading edge and in the wake. The grid has 319 points around the blade with roughly 100 points on each surface and 60 points downstream. There are 45 points from the blade to midpitch, or 90 points blade-to-blade. The first grid point from the blade surface is located $0.0025 \mathrm{~mm}(0.0001 \mathrm{in}$.) from the blade surface, which corresponds to about one-tenth of the thickness of the coatings applied to the blade, or to about $y^{+}=2.5$ in turbulent wall units.

Solutions were all run for 2500 iterations, which reduced the maximum residual between four and five orders of magnitude. Solution times were about 4.5 minutes on a Cray Y-MP.

\section{NUMERICAL RESULTS}

Three different blade geometries were analyzed with the quasi3D analysis code: i) the baseline blade; ii) the baseline blade with a constant thickness added normal to the blade surface; iii) the thickened blade with a non-circular leading edge. The non-circular leading edge case was analyzed to assess the effect of leading edge manufacturing imperfections on the predicted performance. The non-circular shape used was a generic shape developed on the basis of eyelash inspections of several blades. Detailed views of the grids around the leading edges are shown in Figure 16.

The thickness added to each blade surface was $0.025 \mathrm{~mm}$ (0.001 in.), which was the coating thickness measured during the experiment. The baseline and smooth-coated blade configurations were modelled by using the baseline geometry and the thickened geometry with the roughness model deactivated. The roughcoated blade was modelled by using the thickened geometry and activating the roughness model. For both the smooth and rough coatings, leading edge roughness due to particle impact damage was modelled by forcing transition at the leading edge.

The analysis code was first run assuming that the leading edge is smooth, i.e. that transition does not occur at the leading edge. For this case the analysis code predicts that transition will occur for both the baseline and thickened blades at about $36 \%$ chord on the suction surface, where it is probably triggered by the pressure rise through the foot of the shock which extends slightly upstream from the main shock in a classic lambda pattern. Transition is predicted at about $29 \%$ chord on the pressure surface. Although the transition locations predicted using the BaldwinLomax model are not considered to be particularly reliable, the results do indicate a sizable laminar flow region, especially on the suction surface.

The overall pressure rise characteristics predicted by the analysis for the baseline and smooth-coated blade are compared to the characteristic measured for the smooth-coated blade in Figure 17. The purpose of Figure 17 is to display trends in the predicted performance deterioration as thickness is added to the leading edge. The shape of the pressure rise characteristic predicted by the quasi-3D analysis will not, in general, agree with that of the actual characteristic due to limitations in the quasi-3D approach, which models 3D flow effects through simple changes in radius and streamtube thickness. The measured baseline performance is therefore not presented in Figure 17, and the measured smoothcoated performance is shown only to indicate the general level of the measured performance deterioration.

The three predicted characteristics shown in Figure 17 are for the baseline blade with natural transition $\left(^{*}\right)$, the smoothcoated blade with natural transition $(\triangle)$, and the smooth-coated blade with transition forced at the leading edge $(\mathrm{X})$. There is also a single point shown for the baseline blade with transition forced at the leading edge (flagged *). The roughness model was deactivated for all of these solutions, i.e. the blade surface was treated as being hydraulically smooth.

For a smooth leading edge the predicted performance deterioration between the baseline blade $\left(^{*}\right)$ and the smooth-coated blade $(\triangle)$ is far less than that observed in the experiment. On the other hand, the deterioration predicted simply by forcing either the baseline (flagged *) or the smooth-coated (X) blade boundary layer to be turbulent from the leading edge while treating the blade surface as hydraulically smooth is in closer agreement with that measured in the experiment for the smooth-coated blade. This result indicates that the performance deterioration observed for the smooth-coated blade is not due to an increase in blade thickness but rather from the boundary layer being tripped at the leading edge due to increased leading edge roughness as a result of particle impact damage. This is certainly a possibility since the smooth coating was relatively soft and therefore resulted in a smooth-coated blade which was more susceptible to damage at the leading edge than was the baseline blade. 


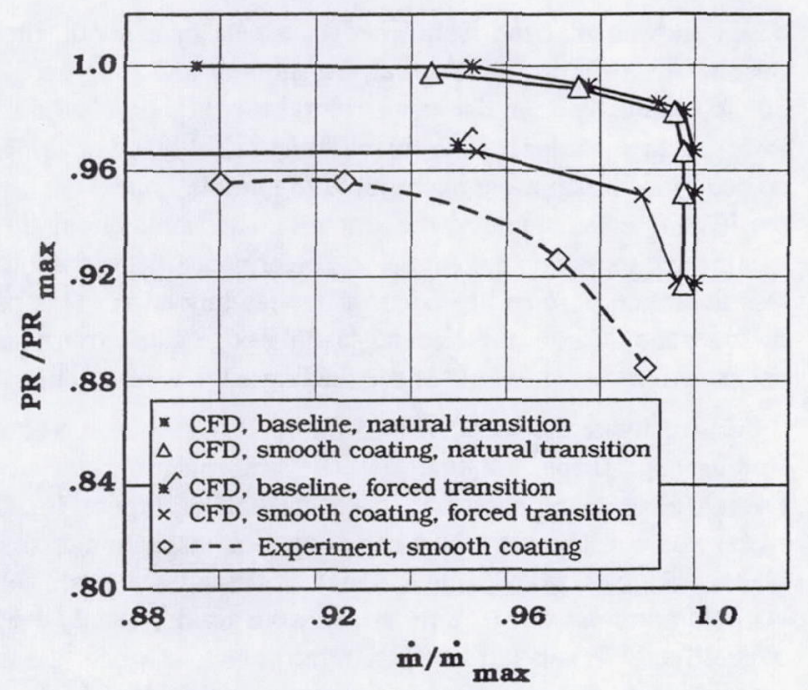

FIGURE 17. COMPARISON BETWEEN PREDICTED AND MEASURED PRESSURE RISE VS MASSFLOW CHARACTERISTICS AT $70 \%$ SPAN FOR THE ROUGH-COATED BLADE

A limited number of predictions were also generated using the full-3D Dawes code. The 3D analysis was performed to investigate the impact of manufacturing tolerances on aerodynamic performance. Therefore, a thickness of $0.062 \mathrm{~mm}(0.0025 \mathrm{in}$.) was added to each surface, which represents the maximum manufacturing tolerance specified for Rotor 37 when it was fabricated. Note that this thickness was 2.5 times that added to the blade for the quasi-3D analysis. The 3D analysis was performed on the baseline blade and on the thickened blade and transition was forced at the leading edge in both cases. The results, which are not shown here, agree qualitatively with the quasi-3D results. The full-3D results indicate a stronger dependence of the choke flow rate on the addition of thickness, but this is probably due in part to the larger thickness added for the $3 \mathrm{D}$ analysis. However, for values of $\dot{m} / \dot{m}_{\max } \leq 0.98$, the full-3D results predict only a $2 \%$ loss in normalized pressure ratio, which agrees with the quasi-3D predictions. Based on this exercise, we conclude that the trends in performance degradation with increased thickness predicted by the quasi-3D analysis are independent of the quasi$3 \mathrm{D}$ solution approach, i.e. both quasi-3D and $3 \mathrm{D}$ analyses predict a very weak dependence between pressure rise capability and added blade thickness.

The rough-coated rotor performance was simulated by running the analysis code with the roughness model activated for equivalent surface roughness heights equal to $1,2,3$, and 4 times that measured for the rough-coated blade in the experiment. All predictions for the rough-coated blade were generated with transition forced at the leading edge, since this procedure gave reasonable results for the smooth-coated blade case when compared to the experimental data. When the code was run in the natural transition mode with the roughness model activated, transition was still predicted to occur far from the leading edge on both the suction and pressure surface. These solutions, which are not shown here, predicted very little additional performance deterioration when

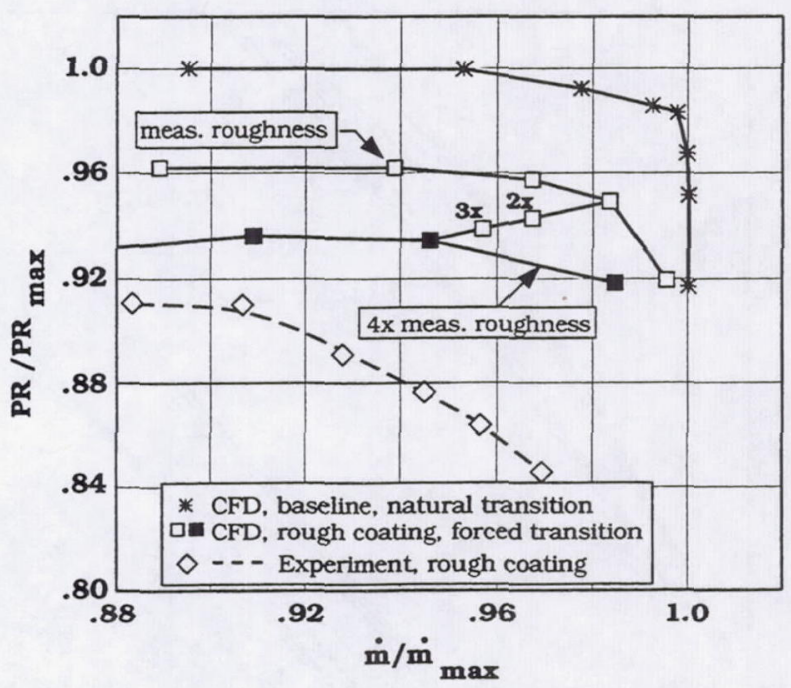

FIGURE 18. COMPARISON BETWEEN PREDICTED AND MEASURED PRESSURE RISE VS MASSFLOW CHARACTERISTICS AT $70 \%$ SPAN FOR THE ROUGH-COATED BLADE

compared to the smooth-coated blade solution with the boundary layer tripped at the leading edge.

The predicted results for the rough-coated and baseline blade are compared to the experimental results for the rough-coated blade in Figure 18. As in Figure 17, the measured performance characteristic for the rough-coated blade is included in the figure only to indicate the measured level of performance deterioration. Two different predicted characteristics are shown for the roughcoated blade. The open symbol curve represents a roughness equal to that measured in the experiment, while the solid symbol curve represents a roughness height which is four times that used in the experiment. The symbols labelled " $2 x$ " and " $3 x$ " show single points calculated for a roughness height equal to 2 and 3 times the measured roughness height. The rough-coated results shown in Figure 18 indicate that the predicted compressor performance characteristics are sensitive to the addition of surface roughness. However, the surface roughness model significantly underpredicts the performance changes measured in the experiment.

It was quite difficult to obtain high-quality LFA measurements near the blade surface due to light reflections from the surface and optical blockage caused by blade twist. The numerical results were therefore used to provide additional insight into the flow behavior near the blade surface by using lines of constant entropy to visualize the predicted boundary layer growth. Entropy levels are highest at the blade surface and decrease to their minimum values upstream of the blade passage. The entropy levels across the shock lie between the upstream and blade surface levels. The smallest entropy level which encompasses the blades but not the shock is therefore a reasonable representation of the boundary layer edge. This entropy level is shown in Figure 19 for the baseline, smooth-coated, and rough-coated cases. The same entropy level is used for each case. The baseline blade results are for natural transition, while the smooth and rough results are for transition forced at the leading edge. The rough-coated result is for a roughness height which is 4 times that measured in the 


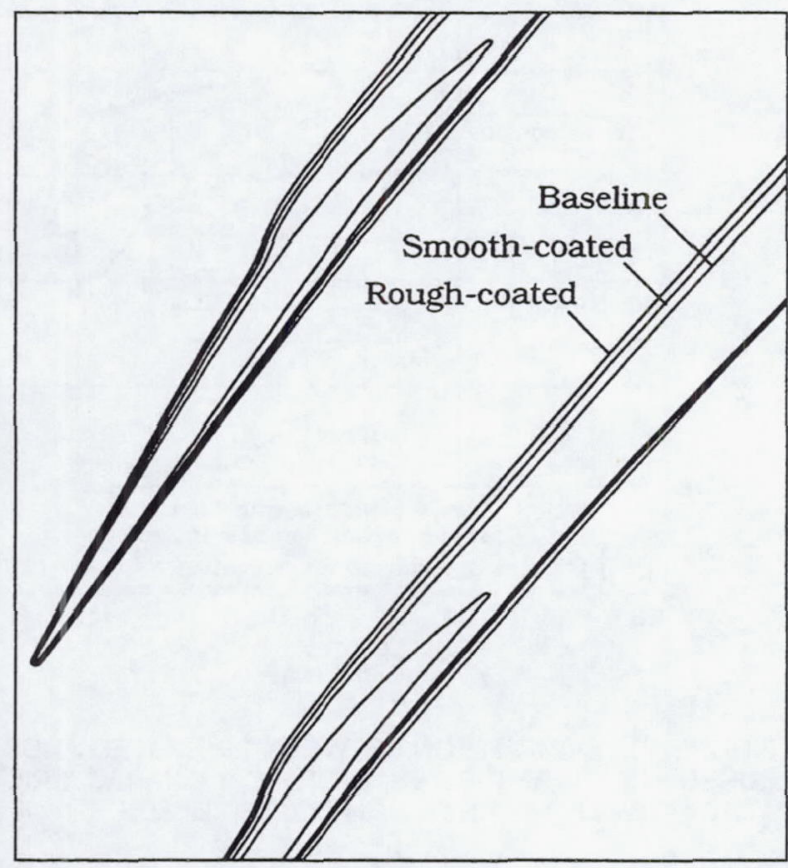

FIGURE 19. PREDICTED BOUNDARY LAYER GROWTH VISUALIZED AS A LOCUS OF CONSTANT ENTROPY

experiment. The results clearly indicate a thickening of the boundary layer near mid-chord, where the passage shock impinges on the blade suction surface. The trend toward increased boundary layer thickness for the coated cases agrees qualitatively with the measured trend toward higher exit Mach numbers in the smoothand rough-coated cases. The predictions also indicate that the changes in boundary layer thickness are greater for the suction surface than for the pressure surface. This result is in qualitative agreement with the partial-coating aerodynamic performance results, which indicated less performance degradation for pressure surface roughness than for suction surface roughness.

LFA measurements did not provide information on the existence of boundary layer separation near the suction surface in the rear of the blade passage due to optical blockage of the LFA laser beams. We therefore inspected the predicted blade-to-blade Mach number distributions for the baseline, smooth-coated, and roughcoated cases in this region to determine if the analysis code predicted boundary layer separation downstream of the shock. This exercise revealed a thin separated zone near the surface for all three cases (baseline, smooth-coated, and rough-coated) with a thickness which is relatively independent of the backpressure. The separation is limited to the first eight grid points from the surface and is therefore quite small, since the surface-normal distance covered by these grid points corresponds to only $1 \%$ of the boundary layer thickness at the trailing edge.

All of the numerical results discussed above were generated using the nominal circular leading edge blade shape shown in the left half of Figure 16. However there are several reasons which might lead one to wonder if a circular leading edge is the proper geometry to use when trying to simulate the experimental measurements. First, the eyelash inspections of several blade leading edges showed that the leading edge is not, in general, circular (as shown in Figure 3). Second, the smooth and rough coatings applied to the blade in the experimental investigation had a much lower surface hardness than the baseline metal blade, making the coated blade much more susceptible to particle impact damage at the leading edge. Finally, the smooth-coated predictions do not capture the experimental trends in performance deterioration unless transition is forced to occur at the leading edge. This raises the question "Can a non-circular leading edge cause transition to occur earlier than it would if the leading edge were circular?"

To investigate the sensitivity of the flow field to a non-circular leading edge shape, the analysis code was run using the faceted leading edge shape shown in the right half of Figure 16. This shape was developed on the basis of eyelash inspection of several blades. Refined grids with 449 points around the blade (about 40 points around the leading edge) were used to study leading edge effects. When run in the natural transition mode, the analysis indicates that transition still occurs on the blade surface far from the leading edge. Furthermore, the analysis indicates that the sharp comers formed by the faceted leading edge shape do not cause the formation of a separation bubble or any strong shock features. In fact the flow expands from the stagnation point all around the leading edge, and only sees a weak adverse pressure gradient when it reaches the flat part of the blade surface. $\mathrm{Cal}$ culations were performed for operating points near choke (low incidence) and near stall (high incidence) and indicate that the non-circular leading edge shape chosen for this analysis does not have a significant impact on the predicted blade row performance at any operating condition. This issue certainly warrants further investigation using better transition models.

\section{CONCLUSIONS}

The results of this investigation indicate that increasing thickness and adding roughness to a transonic axial-flow compressor rotor can result in a significant degradation in overall performance. The nominal coating thickness of $0.025 \mathrm{~mm}(0.001 \mathrm{in}$.) on each blade surface corresponded to an increase in leading edge thickness of $10 \%$ at the hub and $20 \%$ at the tip of the blade. The addition of a smooth coating, which increased the blade thickness without increasing roughness, resulted in a $4 \%$ loss in pressure ratio across the rotor at an operating point near design massflow. The addition of a rough coating of equal thickness with a surface finish of $2.54-3.18 \mu \mathrm{m}$ (100-125 $\mu \mathrm{in}$.), resulted in a $9 \%$ loss in pressure ratio across the rotor at the same operating point. The largest degradation in pressure rise occurs over the outer half of the blade span at design speed.

When assessed at a constant pressure ratio, the adiabatic efficiency degradation at design speed is on the order of 3 points for the smooth coating and $6-8$ points for the rough coating. Aerodynamic efficiency decreases at all speeds tested, even at fully subsonic operating conditions. At 60 percent of design speed, the effect of roughness on the blade boundary layer development is still significant, resulting in a loss in adiabatic efficiency of 1-3 points. Therefore, surface roughness should not be ignored during the manufacture or refurbishment of subsonic blading. 
The conclusions of this investigation are:

1. A detailed investigation into which areas of the blade surface are most sensitive to thickness/roughness effects at design speed identified the leading edge and the front half of the suction surface as critical regions in this regard. All partially-coated configurations in which the leading edge was coated suffered a significant performance degradation when compared to those for which the leading edge was uncoated. In coating the leading edge, we increased both its thickness and roughness. However, flow field predictions generated using both quasi- and full-3D Navier-Stokes codes indicate that adding thickness to the blade has little impact on performance. These facts lead to the suggestion that in the manufacture and repair of transonic axial blading, the blade leading edges should be as smooth as possible and designed to stay that way for as long as possible in service.

2. The flow field predictions generated with a quasi-3D flow solver indicate the existence of significant laminar flow regions on both the pressure and suction surface of the airfoil when the blade boundary layers are allowed to undergo natural transition. This result suggests that fan blades, which operate in a clean flow environment free of upstream blades and struts, may be more susceptible to performance deterioration due to leading edge erosion than are core compressor blades, which operate in a highly disturbed environment.

3. The simple roughness model used in the quasi-3D calculations yields the proper trends in performance deterioration but underpredicts the impact of surface roughness on performance. Reasonable agreement between flow field predictions and the experimental data for the rough-coated blade cannot be achieved by using roughness levels which are higher than those measured in the experiment.

4. The quasi-3D analysis of a non-circular leading edge indicates that transition at the leading edge is not triggered simply by the non-circular leading edge shape considered herein.

5. Laser anemometer measurements indicate that the sensitivity of Rotor 37 to thickness/roughness at design speed is primarily due to blockage changes in the rear of the blade passage. Coating the blade increases the suction surface boundary layer thickness upstream of the shock, which results in a significant thickening of the suction surface boundary layer downstream of the shock/boundary layer interaction. The resulting blockage reduces the overall diffusion across the blade passage, thereby reducing the pressure and temperature rise through the rotor. The rather tight throat area margin and high exit Mach numbers in Rotor 37 make it quite sensitive to small blockage changes. A rotor which features lower exit Mach numbers than Rotor 37 could therefore be expected to be less sensitive to added thickness and roughness.

\section{ACKNOWLEDGMENTS}

The authors would like to thank the NASA Lewis Research Center for supporting the research effort reported herein, and $\mathrm{Mr}$.
Jerry Wood for performing the full-3D Dawes-code analysis of added thickness effects and for his helpful comments. The last author would particularly like to thank Sermatech International for their support of his participation in this research effort. Finally, the authors would like to thank Aviation Product Support Inc. for providing sample fan blades for inspection of in-service blade surface deterioration.

\section{REFERENCES}

Alber, I.E., Bacon, J.W., Masson, B.S. and Collins, D.J., 1973, "An Experimental Investigation of Turbulent Transonic ViscousInviscid Interactions," AIAA Journal, Vol. 11, No. 5, pp. 620627.

Baldwin, B.S., and Lomax, H., 1978, "Thin-Layer Approximation and Algebraic Model for Separated Turbulent Flows," AIAA Paper 78-257.

Boyle, R.J., 1993, "Prediction of Surface Roughness and Incidence Effects on Turbine Performance," ASME Paper No. 93-GT-280.

Boyle, R.J., and Civinskas, K.C., 1991, "Two-Dimensional Navier-Stokes Heat Transfer Analysis for Rough Turbine Blades," AIAA Paper No. 91-2129, also NASA TM 106008.

Boynton, J.L., Tabibzadeh, R., and Hudson, S.T., 1992 , "Investigation of Rotor Blade Roughness Effects on Turbine Performance," ASME Paper No. 92-GT-297.

Cebeci, T., and Chang, K. C., 1978, "Calculation of Incompressible Rough-Wall Boundary Layer Flows," AIAA Journal, Vol. 16, July, 1978, pp 730-735.

Chima, R.V., 1987, "Explicit Multigrid Algorithm for QuasiThree-Dimensional Viscous Flows in Turbomachinery," Journal of Propulsion and Power, Vol. 3, No. 5, pp. 397-405.

Covey, R.R., Mascetti, G.J., and Roessler, W.U., 1978, “Examination of Commercial Aviation Operational Energy Conservation Strategies," The Aerospace Corporation, Aerospace Report No. ATR-79(7761)-1, Vol. 2.

Dawes, W.N., 1988, "Development of a 3-D Navier Stokes Solver for Application to all Types of Turbomachinery," ASME Paper No. 88-GT-70.

Proceedings of the DOE/FAA Symposium on Commercial Aviation Energy Conservation Strategies, April, 1981.

Koch, C.C., and Smith, L.H., 1976, "Loss Sources and Magnitudes in Axial-Flow Compressors," ASME Journal of Engineering for Power, Vol. 98, No. 3, pp. 411-424.

Kramer, W.H., Paas, J.E., Smith, J.J., and Wulf, R.H., 1980, "CF6-6D Engine Short-Term Performance Deterioration," NASA CR-159830.

Liepmann, H.W., and Roshko, A., 1967, Elements of Gasdynamics, Wiley, New York.

Moore, R.D., and Reid, L., 1980, "Performance of a Single-Stage Axial-Flow Transonic Compressor with Rotor and Stator Aspect Ratios of 1.19 and 1.26, Respectively, and with Design Pressure Ratio of 2.05," NASA TP 1659. 
Moses, J.J., and Serovy, G.K., 1951, "Effect of Blade-Surface Finish on Performance of a Single-Stage Axial-Flow Compressor," NASA RME51c09.

Nichols, C. E. Jr., 1987, "Preparation of Polystyrene Microspheres for Laser Velocimetry in Wind Tunnels," NASA TM 89163.

Reid, L., and Urasek, D.C., 1973, "Experimental Evaluation of the Effects of a Blunt Leading Edge on the Performance of a Transonic Rotor," ASME Journal of Engineering for Power, Vol. 95, No. 3, pp 199-204.

Reid, L., and Moore, R.D., 1978, "Design and Overall Performance of Four Highly-Loaded, High-Speed Inlet Stages for an Advanced High-Pressure-Ratio Core Compressor," NASA TP 1337.

Roelke, R.J., and Haas, J.E., 1982, “The Effect of Rotor Blade
Thickness and Surface Finish on the Performance of a Small Axial Flow Turbine," ASME Paper 82-GT-222.

Sallee, G.P., Kruckenburg, H.D., and Toomey, E.H., 1978, “Analysis of Turbofan Engine Performance Deterioration and Proposed Follow-on Tests," NASA CR-134769.

Strazisar, A.J., Wood, J.R., Hathaway, M.D., and Suder, K.L., 1989, "Laser Anemometer Measurements in a Transonic AxialFlow Fan Rotor," NASA TP 2879.

Suder, K.L., and Celestina, M.L. 1994, "Experimental and Computational Investigation of the Tip Clearance Flow in a Transonic Axial Compressor Rotor," presented at the 39th ASME International Gas Turbine and Aeroengine Congress and Exposition, The Hague, June. 
Public reporting burden for this collection of information is estimated to average 1 hour per response, including the time for reviewing instructions, searching existing data sources, gathering and maintaining the data needed, and completing and reviewing the collection of information. Send comments regarding this burden estimate or any other aspect of this Peports, 1215 Jefferson Davis Highway, Suite 1204, Arlington, VA 22202-4302, and to the Office of Management and Budget, Paperwork Reduction Project (0704-0188), Washington, DC 20503.

\begin{tabular}{|l|l|l}
\hline 1. AGENCY USE ONLY (Leave blank) & $\begin{array}{c}\text { 2. REPORT DATE } \\
\text { June } 1995\end{array}$ & $\begin{array}{r}\text { 3. REPORT TYPE AND DATES COVERED } \\
\text { Technical Memorandum }\end{array}$ \\
\hline
\end{tabular}

\section{TITLE AND SUBTITLE}

5. FUNDING NUMBERS

The Effect of Adding Roughness and Thickness to a Transonic Axial

Compressor Rotor

6. $A U T H O R(S)$

WU-505-62-52

Kenneth L. Suder, Rodrick V. Chima, Anthony J. Strazisar, and William B. Roberts

\section{PERFORMING ORGANIZATION NAME(S) AND ADDRESS(ES)}

National Aeronautics and Space Administration

Lewis Research Center

Cleveland, Ohio 44135-3191

PERFORMING ORGANIZATION REPORT NUMBER

E-9709

9. SPONSORING/MONITORING AGENCY NAME(S) AND ADDRESS(ES)

10. SPONSORING/MONITORING

AGENCY REPORT NUMBER

National Aeronautics and Space Administration

Washington, D.C. 20546-0001

NASA TM-106958

11. SUPPLEMENTARY NOTES

Prepared for the 39th International Gas Turbine and Aeroengine Congress and Exposition sponsored by the American Society of Mechanical Engineers, The Hague, Netherlands, June 13-16, 1994. Kenneth L. Suder, Rodrick V. Chima, and Anthony J. Strazisar, NASA Lewis Research Center; William B. Roberts, Flow Application Research and Sermatech International Inc. Fremont, California. Responsible person, Kenneth L. Suder, organization code 2640, (216) 433-5899.

12a. DISTRIBUTION/AVAILABILITY STATEMENT

12b. DISTRIBUTION CODE

Unclassified-Unlimited

Subject Categories 02 and 34

This publication is available from the NASA Center for Aerospace Information, (301) 621-0390.

13. ABSTRACT (Maximum 200 words)

The performance deterioration of a high speed axial compressor rotor due to surface roughness and airfoil thickness variations is reported. A $0.025 \mathrm{~mm}$ ( $0.001 \mathrm{in}$.) thick rough coating with a surface finish of 2.54-3.18 RMS $\mu \mathrm{m}$ (100-125 RMS microinches) is applied to the pressure and suction surface of the rotor blades. Coating both surfaces increases the leading edge thickness by $10 \%$ at the hub and $20 \%$ at the tip. Application of this coating results in a loss in efficiency of 6 points and a $9 \%$ reduction in the pressure ratio across the rotor at an operating condition near the design point. To separate the effects of thickness and roughness, a smooth coating of equal thickness is also applied to the blade. The smooth coating surface finish is $0.254-0.508 \mathrm{RMS} \mu \mathrm{m}$ (10-20 RMS microinches), compared to the bare metal blade surface finish of $0.508 \mathrm{RMS} \mu \mathrm{m}$ (20 RMS microinches). The smooth coating results in approximately half of the performance deterioration found from the rough coating. Both coatings are then applied to different portions of the blade surface to determine which portions of the airfoil are most sensitive to thickness/roughness variations. Aerodynamic performance measurements are presented for a number of coating configurations at $60 \%, 80 \%$, and $100 \%$ of design speed. The results indicate that thickness/roughness over the first $10 \%$ of blade chord accounts for virtually all of the observed performance degradation for the smooth coating, compared to about $70 \%$ of the observed performance degradation for the rough coating. The performance deterioration is investigated in more detail at design speed using laser anemometer measurements as well as predictions generated by a quasi-3D Navier-Stokes flow solver which includes a surface roughness model. Measurements and analysis are performed on the baseline blade and the full-coverage smooth and rough coatings. The results indicate that coating the blade causes a thickening of the blade boundary layers. The interaction between the rotor passage shock and the thickened suction surface boundary layer then results in an increase in blockage which reduces the diffusion level in the rear half of the blade passage, thus reducing the aerodynamic performance of the rotor.

14. SUBJECT TERMS

Surface roughness; Leading edge; Transonic compressor; Laser anemometry 22

\begin{tabular}{|c|c|c|}
\hline $\begin{array}{c}\text { 17. SECURITY CLASSIFICATION } \\
\text { OF REPORT } \\
\text { Unclassified }\end{array}$ & $\begin{array}{c}\text { 18. SECURITY CLASSIFICATION } \\
\text { OF THIS PAGE } \\
\text { Unclassified }\end{array}$ & $\begin{array}{c}\text { 19. SECURITY CLASSIFICATION } \\
\text { OF ABSTRACT } \\
\text { Unclassified }\end{array}$ \\
\hline
\end{tabular}

